\title{
Anamorphic Projection: Analogical/Digital Algorithms
}

\author{
Francesco Di Paola • Pietro Pedone • \\ Laura Inzerillo • Cettina Santagati
}

Published online: 27 November 2014

(C) Kim Williams Books, Turin 2014

\begin{abstract}
The study presents the first results of a wider research project dealing with the theme of "anamorphosis", a specific technique of geometric projection of a shape on a surface. Here we investigate how new digital techniques make it possible to simplify the anamorphic applications even in cases of projections on complex surfaces. After a short excursus of the most famous historical and contemporary applications, we propose several possible approaches for managing the geometry of anamorphic curves both in the field of descriptive geometry (by using interactive tools such as Cabrì and GeoGebra) and during the complex surfaces realization process, from concept design to manufacture, through CNC systems (by adopting generative procedural algorithms elaborated in Grasshopper).
\end{abstract}

Keywords Anamorphosis Anamorphic technique Descriptive geometry Architectural geometry Generative algorithms Free form surfaces

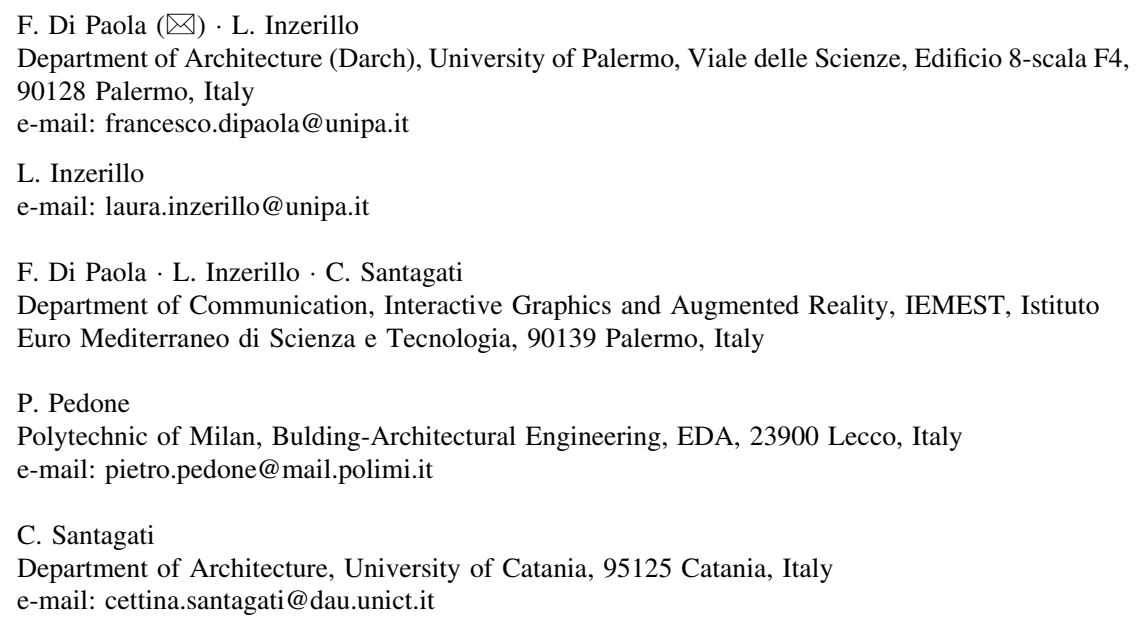




\section{Introduction}

Anamorphosis ${ }^{1}$ is a geometrical procedure for representing shapes on surfaces: the projected image is only recognizable from a predetermined point, and appears deformed from all other positions.

This specific topic-which dates back to the fourteenth century, but was refined in its scientific rigor in Europe between the fifteenth and sixteenth centuries-offers many opportunities for interdisciplinary research in the field of geometry applied to architecture, figurative arts, visual perception, history of architecture and industrial design.

The application of the anamorphic process requires mastery and skill in the use of different techniques of the science of representation aimed at finding the rule for deforming and regenerating represented images. Our work in progress continues the research conducted by researchers of the Drawing School of the Engineering Faculty at the University of Palermo (Inzerillo 2008), which has always promoted experimentation and innovation in of the application of descriptive geometry to topics based on the relationship between geometry and architecture/engineering.

Here we investigate new digital techniques through which the applications of anamorphisms are simplified even in the case of projections on complex surfaces. This paper is organized as follows. Section 2 gives a short overview of the most famous historical and contemporary applications. Section 3 we introduce some possible approaches that allow management of the geometry of anamorphic curves in the field of descriptive geometry (by using interactive tools such as Cabrì and GeoGebra). Section 4 presents experimental outcomes dealing with the process of producing complex surfaces from concept design to manufacture through CNC systems (by adopting generative procedural algorithms elaborated in Grasshopper). We close the presentation with a discussion of the advantages of the method and directions for future work.

\section{From the Origin to Digital Representation}

The first known testimonies of the use of anamorphosis can be found in paintings from the second half of the fourteenth century. Among the most famous are the Pala di Brera by Piero della Francesca (1472), The Ambassadors by Hans Holbein the Younger (1533), and the collection of unpublished anamorphic drawings of the Codex Atlanticus by Leonardo da Vinci (1478-1519). The technique, later referred to as optic anamorphosism, arose as a consequence of an intuition that re-elaborates the theoretical foundations of perspective, already codified between the fourteenth and fifteenth centuries by eminent artists such as Ambrogio Lorenzetti, Filippo Brunelleschi, Masaccio, Leon Battista Alberti, and Albrecht Dürer. The optic artifice allows projection of a shape onto a surface such that it can only be read as its real, undistorted form from a specific point of view, placed wherever the author

\footnotetext{
${ }^{1}$ Neologism of the seventeenth century, from the Greek $\alpha \dot{v} \alpha \mu O ́ \rho \phi \omega \sigma 1 \varsigma$ ("reforming"), derivation of

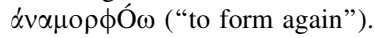


decides. To realize an optic anamorphism to the artist must carry out a mechanicaloptical procedure that allows him to transfer the preparatory drawing from the paper to the wall; once realized, the anamorphic image can be read, in its real shape, from a specific point without using special devices (Fig. 1).

Among the treatise writers who studied and investigated anamorphosis we can mention Leonardo da Vinci, Daniele Barbaro, Jacopo Barozzi da Vignola, Giovanni Paolo Lomazzo, Gaspard Schott, Athanasius Kircher and Jean François Nicéron, who wrote the treatise La perspective curieuse (Nicéron 1638; Lomazzo 1585; Schott 1657) (Fig. 2).

Among the most famous examples of anamorphosis we find Piero della Francesca, in Sacra Conversazione (1475), where the object of anamorphosis is a suspended egg that turns in a sphere if observed from a particular point of view
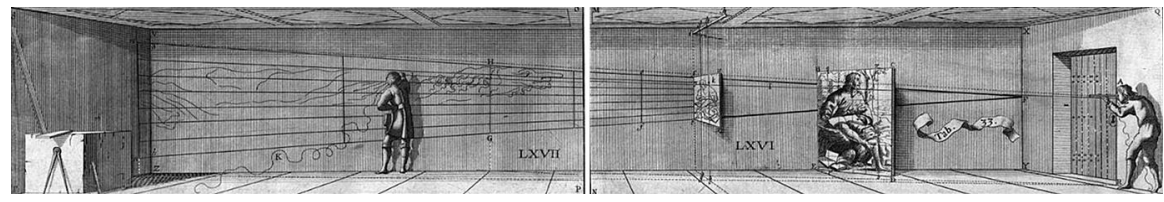

Fig. 1 Scheme of inverse perspective and room reconstruction, procedural methodologies for drawing big sized anamorphic images (Nicéron 1638: Pls. LXVII and LXVI), http://www.books.google.com, figure re-elaborated by authors

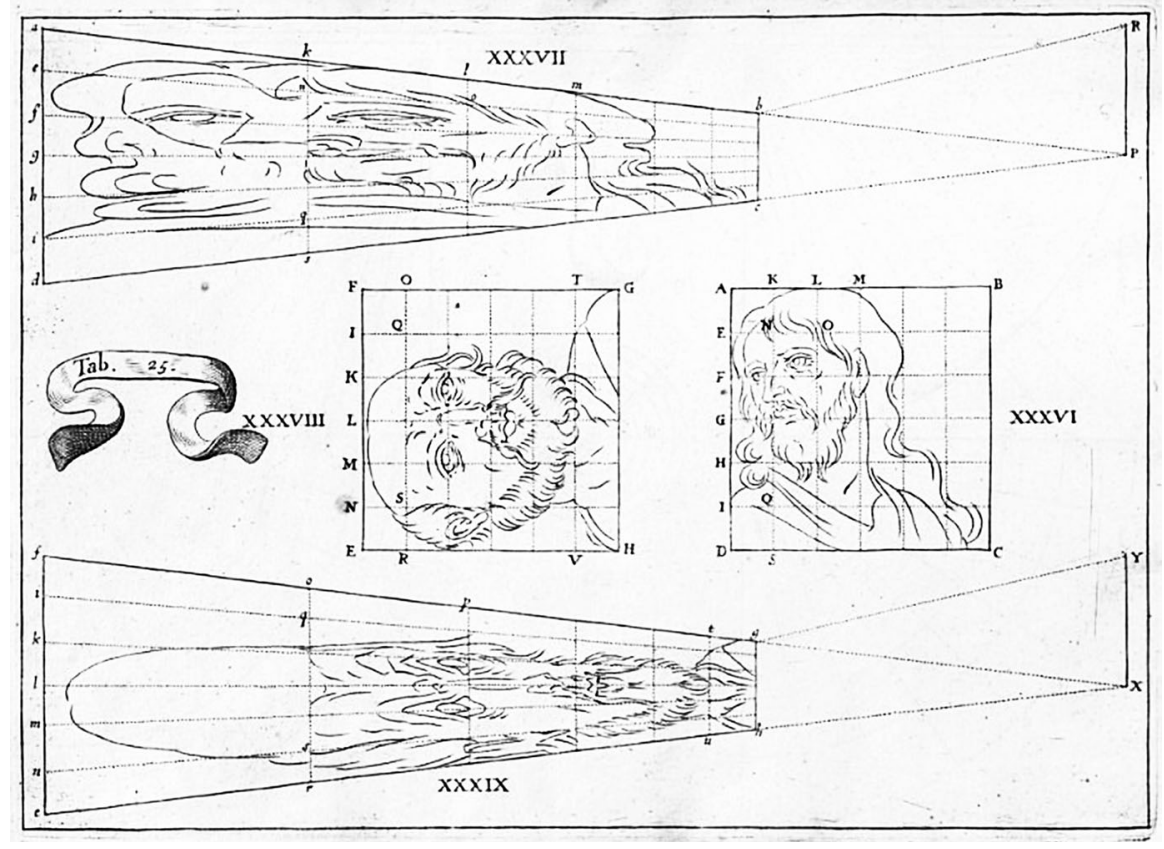

Fig. 2 Images showing the genesis of anamorphic perspectives of human portraits onto a plane surface (Nicéron 1638, p. 415, Pls. XXXVII, XXXIX), http://www.books.google.com 
Fig. 3 Left Pala di Brera, by Piero della Francesca.

Pinacoteca di Brera, Milan, 1472. The egg in the upper part of the painting, if observed from an oblique point of view placed at the bottom of the Pala, turns into a sphere, http://www.it. wikipedia.org/wiki/Pala_di_ Brera. http://commons. wikimedia.org/wiki/File:Piero_ della_Francesca_046.jpg the reproduction is part of a collection of reproductions compiled by The Yorck Project. The compilation copyright is held by Zenodot Verlagsgesellschaft $\mathrm{mbH}$ and licensed under the GNU Free Documentation License

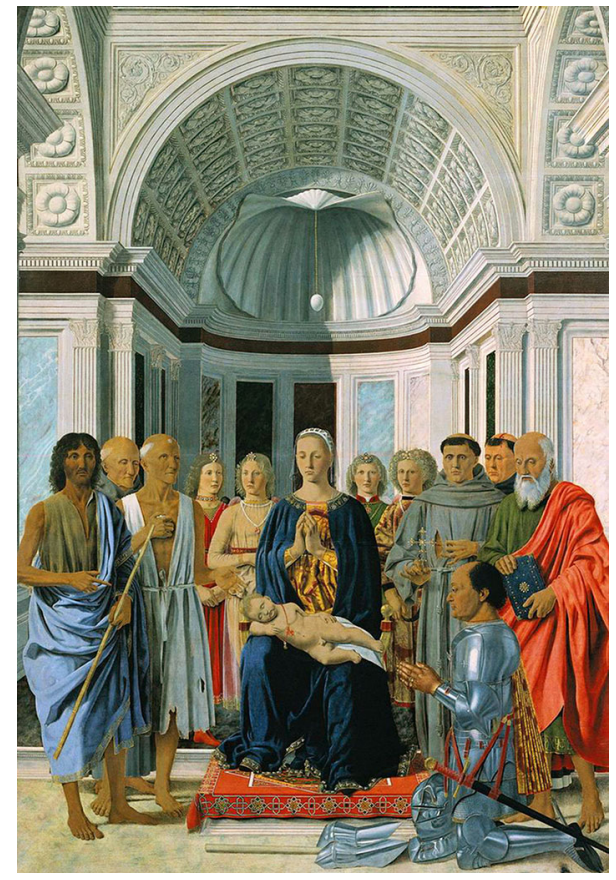

(Fig. 3); the German painter Hans Holbein the Younger, in his famous painting The Ambassadors (1533), in which the distorted shape in the bottom of the frame transforms into a skull (Fig. 4); the two Friars Minor confreres, Jean François Nicéron and Emmanuel Maignan, in the frescos of the galleries of the cloister in the monastery of SS. Trinità dei Monti depicting San Giovanni (1639-1640) (Fig. 5) and San Francesco di Paola (1642) (Fig. 6).

In both these latter cases, the visitor placed at the center of the galleries observes two scenes, that are apparently confused and reached by landscape elements (lakes, rivers, grape harvest scenes, mountains, palm groves and exotic flowers, vessels and far away cities). Furthermore, in both frescos, a big olive tree is used as perspective background.

When the observer arrives at the end of both galleries he discovers, with great surprise, an astonishing effect that is perceived only from that view point: he can observe the optically correct image of the represented saint from the punctum optimum, planned by the author (De Rosa and Cristian 2012: 595-602).

Scientific research in the Renaissance era in the perspective field, in projective geometry and in optics helped to determine, in the Baroque period, new illusionistic spatial effects and mastery of the tricks of stage design (Accolti 1625).

Between the sixteenth and eighteenth centuries, the kinds of painting named "quadraturism" and "trompe-l'oeil" arose and developed; these techniques aimed at the composition of faux architectural perspectives realized at full scale to create illusory effects on walls and ceilings. 
Fig. 4 Center, right The Ambassadors by Hans Holbein the Younger, National Gallery, London, 1533. The anamorphic skull on the floor becomes recognizable only observing the painting from the left side according to an oblique point of view. http://www.it.wikipedia. org/wiki/Gli_ambasciatori (Holbein_il_Giovane) Author: Lisby, licenza Creative Commons Attribution 2.0 Generic. https:// creativecommons.org/licenses/ by/2.0/legalcode, no change to the figure, https://flic.kr/p/ $6 \mathrm{VsvNa}$
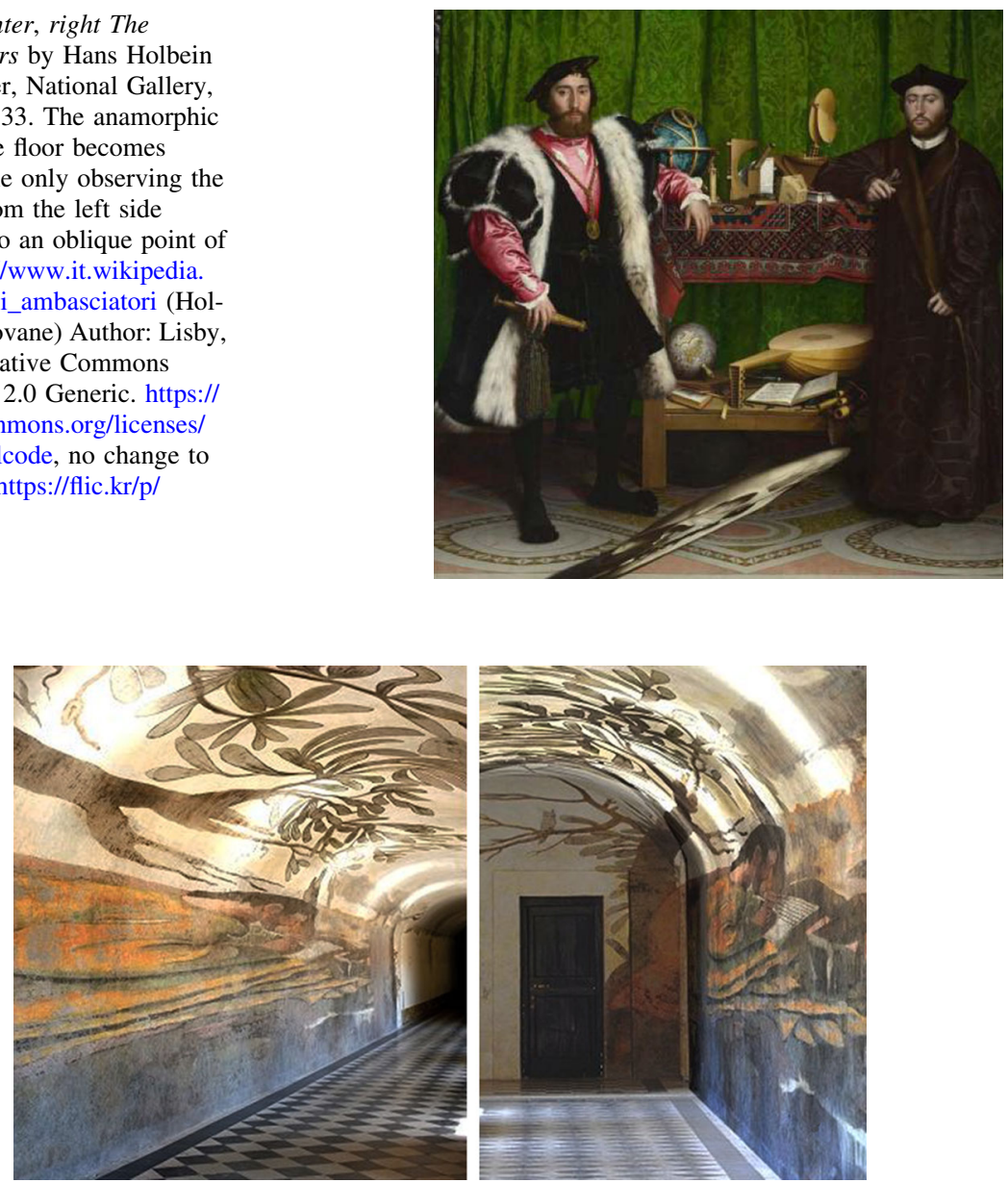

Fig. 5 Jean François Nicéron, anamorphic fresco of the Gallery of the Monastery of Trinità dei Monti in Rome, 1640. On the left, the figure shows the central part of the fresco as it appears walking through the corridor. On the right, there is the image of Saint John the Evangelist as appears from the privileged point of view (De Rosa and Cristian 2012, p. 597)

The painters used the concepts of anamorphosis in the creation of their works, with extreme skill and mastery, creating wonderful examples on the curved surfaces of apses and niches, over large areas of aristocratic salons or on the articulated vaults of churches.

We can cite, among the examples of anamorphosis on large scale, the apse of the church of Santa Maria in San Satiro in Milan created by Donato Bramante (1483), the corridors of Palazzo Spada in Rome by Francesco Borromini (1540), and the trompe-l'oeil scenography of Palladio's Teatro Olimpico in Vicenza designed by Vincenzo Scamozzi (1584).

The architect and painter Andrea Pozzo was one of the greatest exponents of illusory architecture as well as a theorist of perspective. The frescos on the ceiling of 

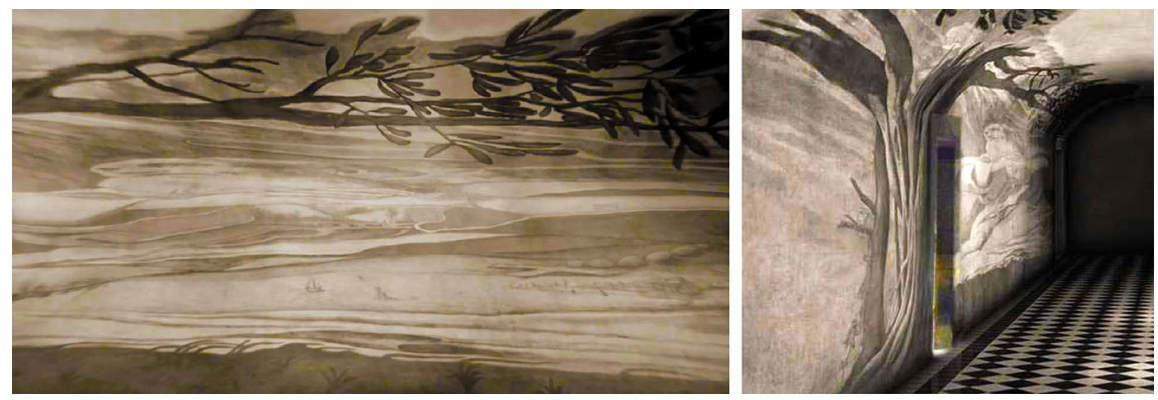

Fig. 6 Emmanuel Maignan, anamorphic fresco of the Gallery of the Gallery of Trinità dei Monti monastery in Rome, 1642. On the left, the figure shows the central part of the fresco as it appears walking through the corridor. On the right, Saint Francesco of Paola kneeling in prayer (Di Lazzaro and Murra 2013, pp. 13-14)

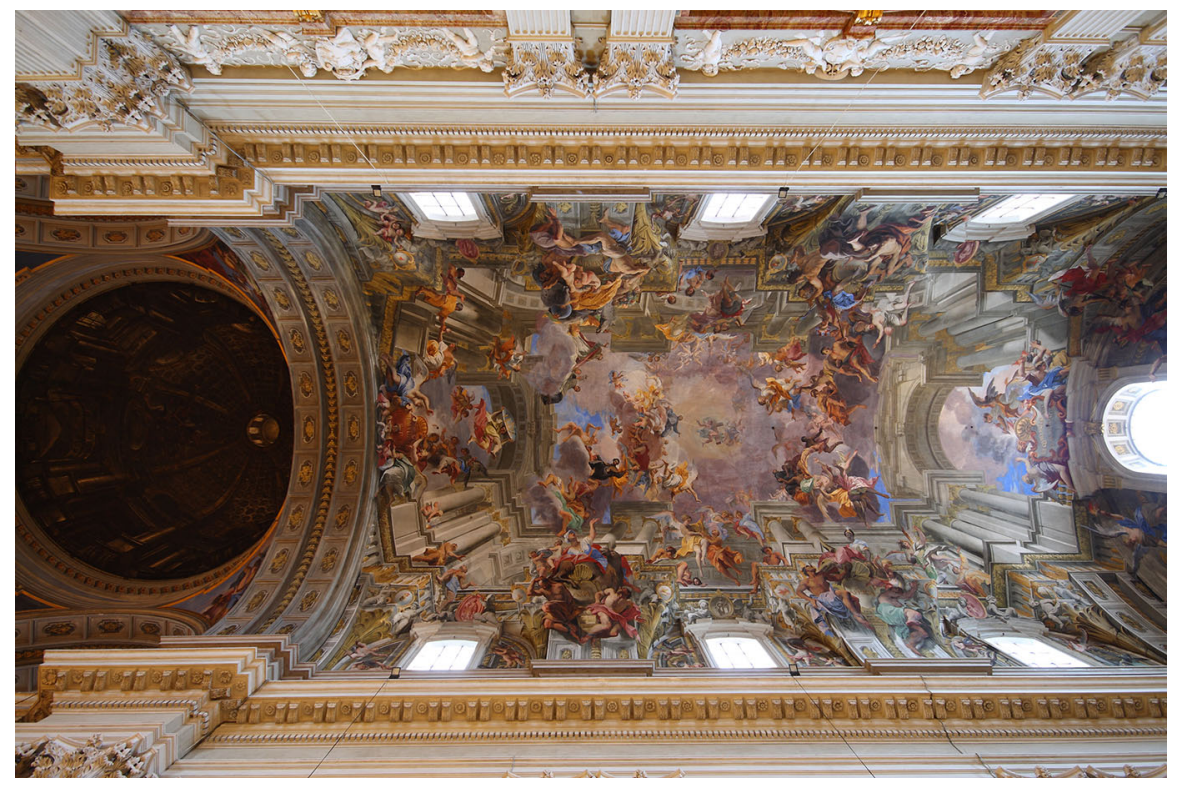

Fig. 7 Andrea Pozzo, Saint Ignatius's Church in Rome, 1685. Quadrature of the false dome and quadrature of the nave. http://www.it.wikipedia.org/wiki/Andrea_Pozzo. Author: Bruce McAdam, licenza Creative Commons Attribution-ShareAlike 2.0. https://creativecommons.org/licenses/by-sa/2.0/ legalcode, no change to the figure: https://flic.kr/p/5TP5GB

the nave and the false dome S. Ignazio in Rome are a clear examples of his art (Fig. 7). For the dome a canvas $13 \mathrm{~m}$ in diameter represents a dome supported by a drum with columns.

To fully admire the perspective illusion, the observer should stand on the point that is indicated by a marble disk. We refer to "catoptric" or "dioptric" anamorphosis depending on whether the studied phenomenon is reflection or refraction and when it is necessary to take advantage of external devices to see the 
Fig. 8 Example of reflection anamorphic projection on a mirroring cylindrical surface, by Hungarian artist István Orosz, 1994. http://www.en.wikipedia. org/wiki/File:Anamorph_with_ column0.jpg. Author: Pazsit Ulla, licenza Creative Commons Attribution-2.5 Generic. http:// creativecommons.org/licenses/ by $/ 2.5 /$ legalcode, no change to the figure

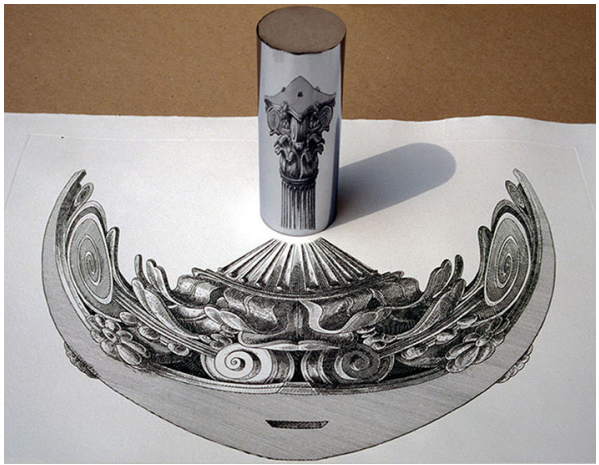

Fig. 9 Scheme on a plane of a reflection anamorphic projection on a conical mirroring surface of a human portrait (Nicéron 1638: p. 406, Pl. XXVII), http://www. books.google.com

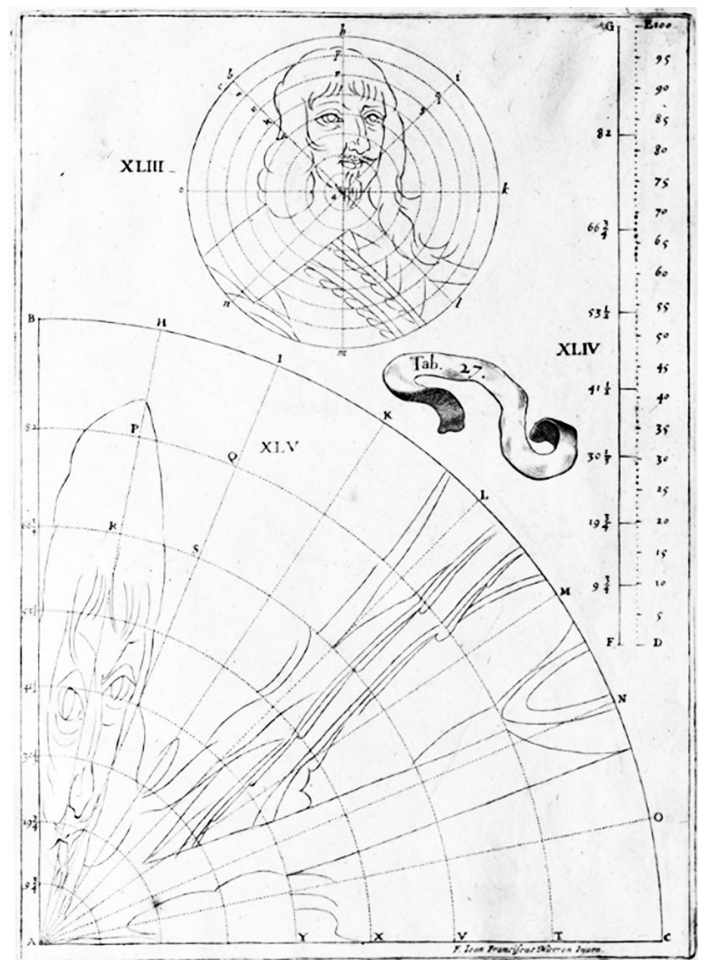

anamorphic image. In this case, the undistorted reading of the anamorphic shape in correct proportion is only possible by means of an auxiliary reflecting or refracting device suitably placed on the two-dimensional construction of the geometrical drawing. These mirror-decoding instruments are named "anamorphoscopes" and can be spherical, cylindrical, conical or polyhedral; they concern reduced scales of representation in comparison with optic anamorphosis (Fig. 8). Nicéron carried out the first experimentations in this field, and gave detailed geometrical procedures for designing and realizing a cylindrical or conical anamorphic drawing, (Fig. 9). 
Beyond the famous and historical scientific experiments in optical-perceptive field, in our own day interest in this aspect of representation has been reawakened in the fields of media and advertising, industrial design, decorative art, theatrical scenic design, architectural and urban planning fields, where we find several examples that demonstrate the fertility of experimentation. One of the practical uses of anamorphic effects in daily life is found in text written on highways where an optical correction that allows drivers to read the road signs in the correct proportions. Another example is found in the advertising texts drawn on sporting stadiums, which are distorted on the playing surface but are clearly visible in correct proportion when viewed from the angle of the television cameras.

Other very interesting contemporary examples are provided by international artists such as the Spanish Eduardo Relero, the Swiss Felice Varini, the Hungarian István Orosz and the English Julian Beever, who also work also in urban contexts creating very effective trompe-l'oeil images by using anamorphic techniques (Figs. 10, 11, 12, 13, 14, 15).
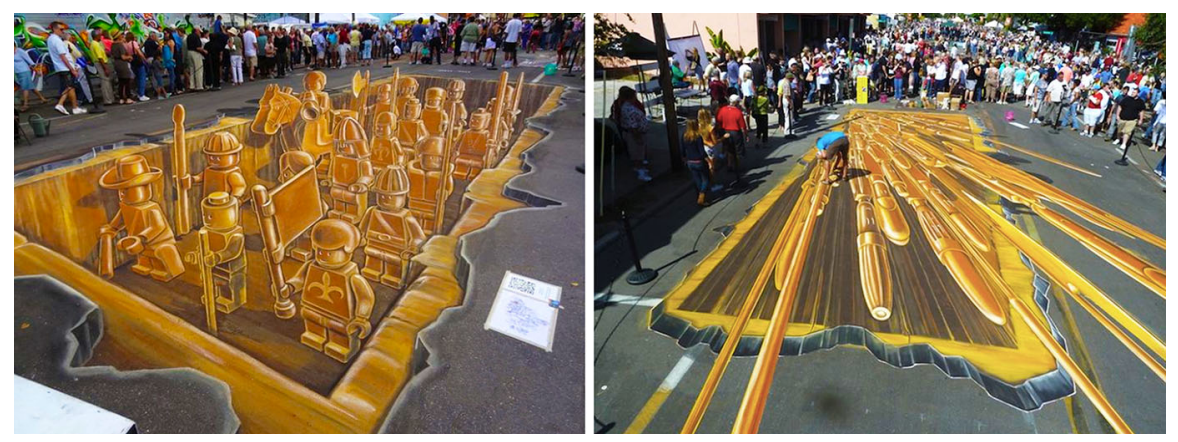

Fig. 10 Leon Keer, Lego Army, IV Chalk Festival in Sarasota, Florida, USA 2011. On the left, anamorphosis painted on the road observed from the privileged point of view; on the right, the same drawing observed from a position opposite the perspective point. rel-univ@enea.it
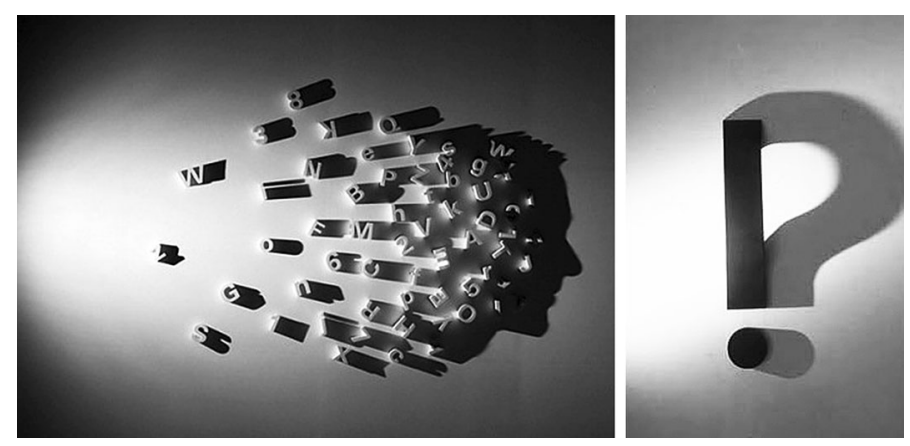

Fig. 11 Lights and shadows, original examples of anamorphosis that test our perception of reality and of all the surroundings. Two installations of the Korean artist Kumi Yamashita: on the left, Profile, Microsoft Art Collection, Washington, USA 1994; on the right, Question mark, commissioned by Namba Parks Tower, Osaka Japan 2003. http://www.kumiyamashita.com/ 

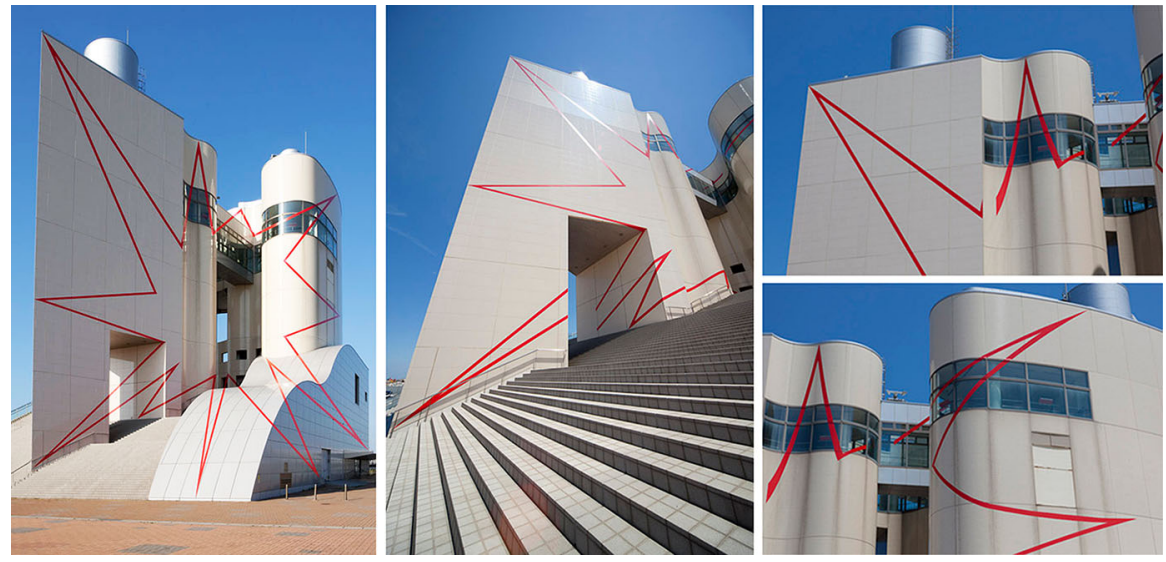

Fig. 12 Felice Varini, Zigzag entre Le Cercle et la tou, Niigata, Japan 2009. An example of a minimalist anamorphic installation on a modern architectural work. http://www.varini.org/
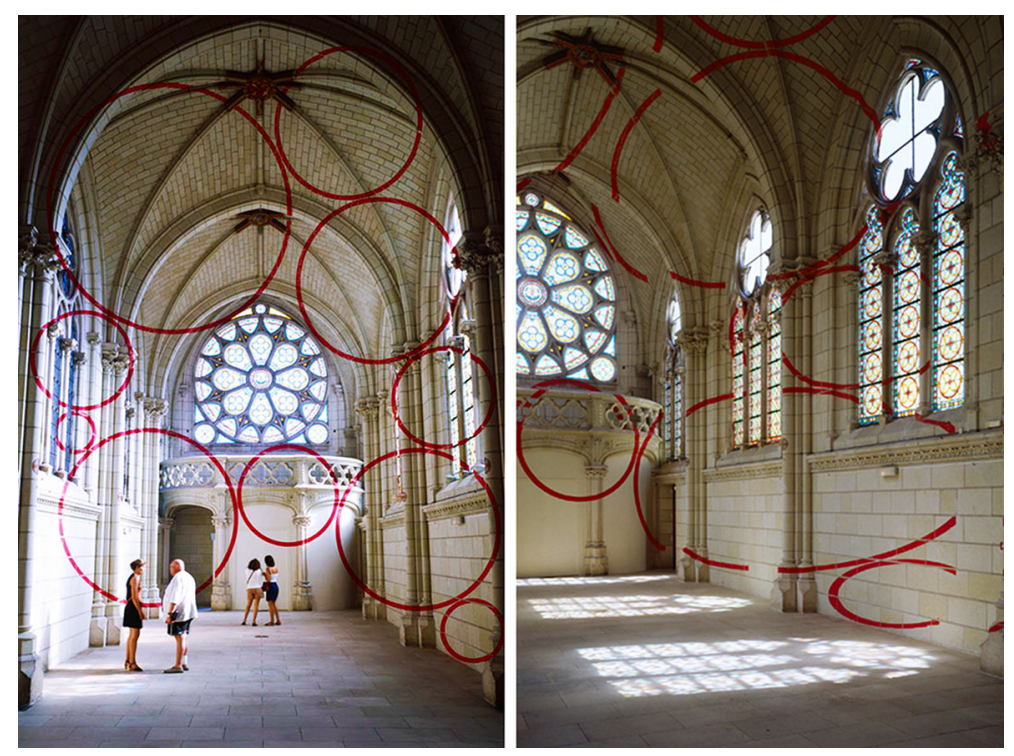

Fig. 13 Felice Varini, Encerclement à dix, Centre d'Art Contemporain, Thouars, France 1999. An example of a large-scale anamorphic installation on an ancient architectural work. The anamorphic projection is applied on a set of planar, curve and slope surfaces in respect to the observer; the technique used is stencil. http://www.varini.org/

The development of informatics technologies in graphical-digital representation contribute to experiment the anamorphosis techniques creating new magnificent and engaging scenarios able to surprise and touch the audience. Nowadays companies specialized into the creation and managing of shows for events and special occasions use innovative techniques such as digital anamorphic projection and special effects. 

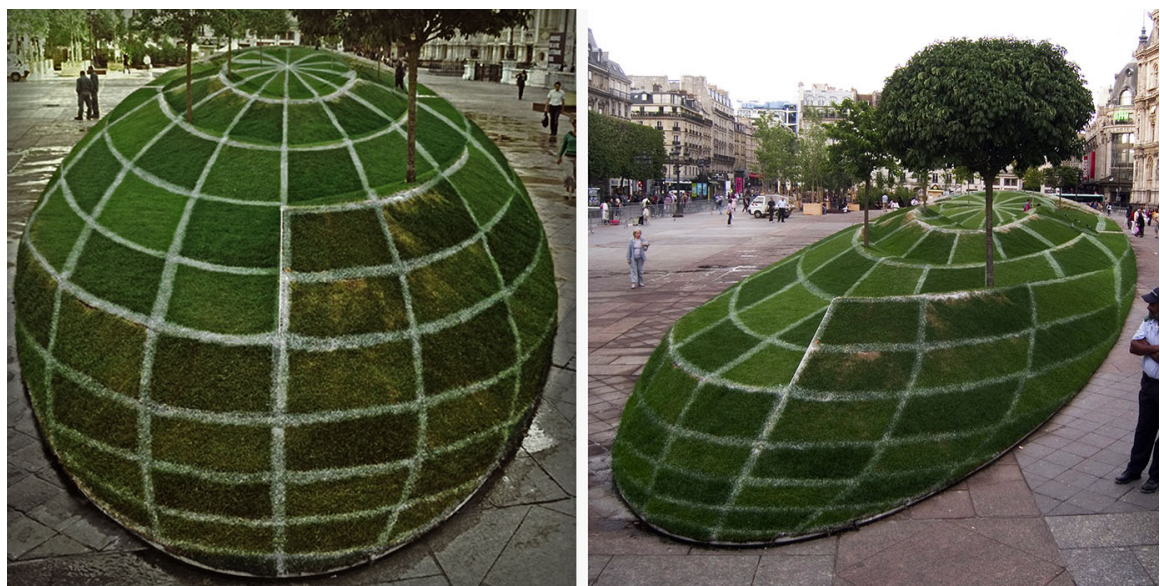

Fig. 14 Qui croire? a land art work of the French François Abelanet, Paris, Place de l'Hôtel de Ville, summer 2011. A bizarre temporary urban installation that represents a flowerbed shaped as a 3D anamorphic globe of about $1.500 \mathrm{sm}$. (Right) Author: Groume, licenza Creative Commons AttributionShareAlike 2.0 Generic. https://creativecommons.org/licenses/by-sa/2.0/legalcode, no change to the figure: https://flic.kr/p/a2szkK. (Left) Autore: r. g-s, licenza Creative Commons Attribution-ShareAlike 2.0 Generic. https://creativecommons.org/licenses/by-sa/2.0/legalcode, no change to the figure: https://flic.kr/ $\mathrm{p} / \mathrm{a} 1 \mathrm{CCZB}$

Fig. 15 Anamorphic shadow in perspective. Model belonging to the collection Perspectiva artificialis at the Laboratory of Mathematical Machines of University of Modena and Reggio Emilia (Martinez et al. 2008). http://www.

macchinematematiche.org/, info@macchinematematiche.org

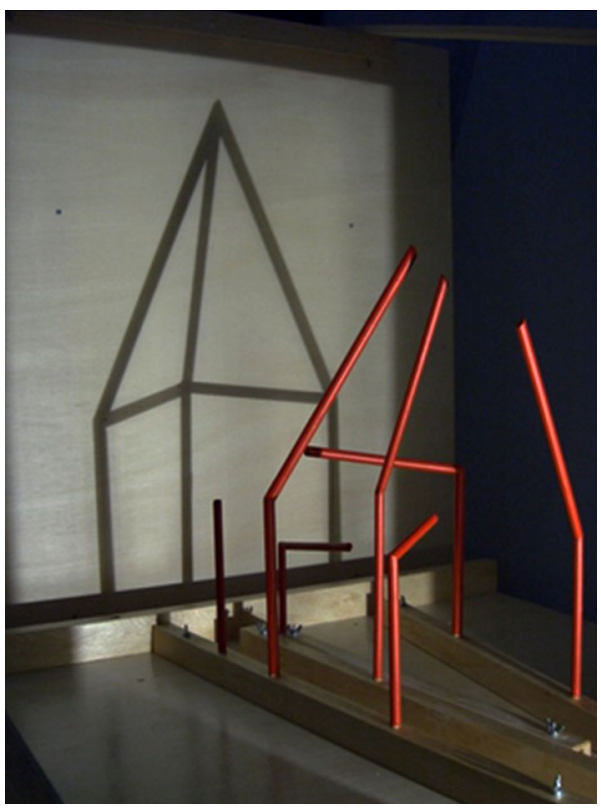

This particular technique is called "3D projection mapping" and is successfully used in original shows relating to issues connected to popular and religious tradition or entertainment (Fig. 16). It is possible to "map" the building architecture, by 

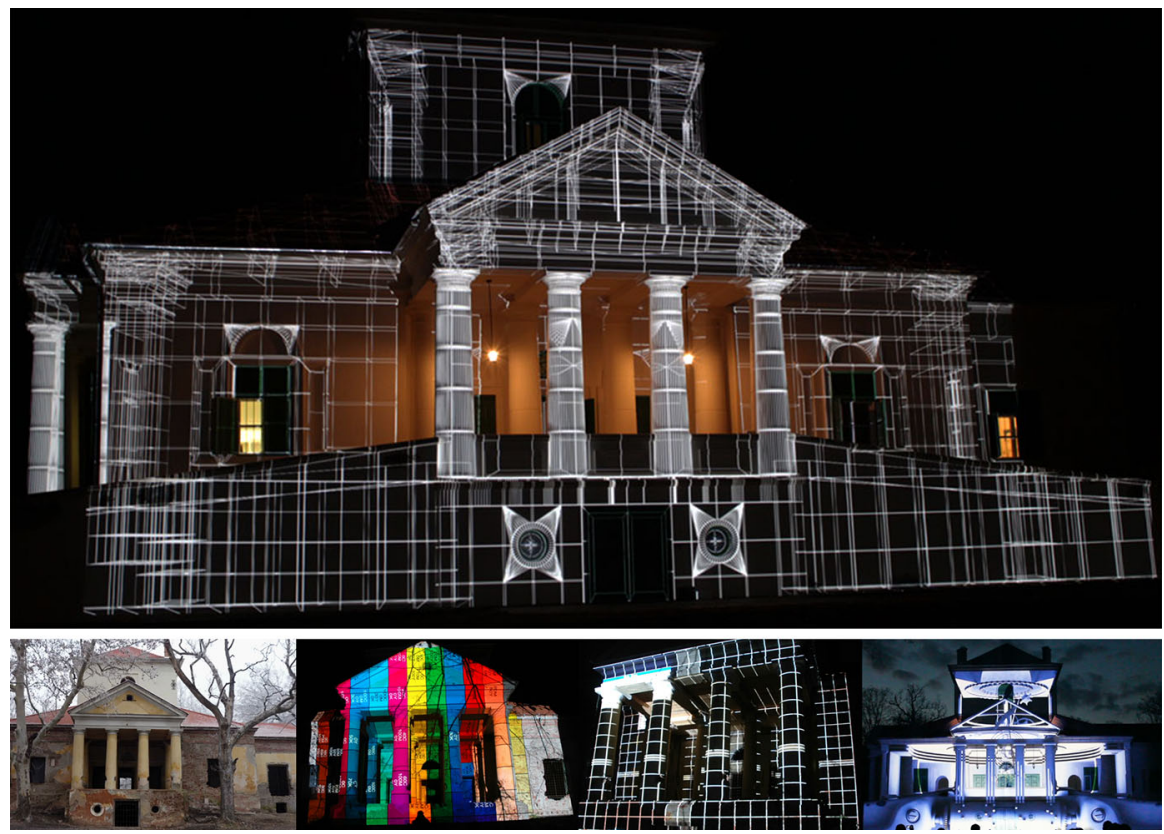

Fig. 16 Bréda Kastély, Lőkösháza, Budapest, Hungary 2013. Site chosen to test 3D projection architectural mapping techniques. http://www.3dmapping.it, http://www.vimeo.com/bordos/

creating a three-dimensional model of the surface, which allows you to interact and play with the building shapes, having the illusion that the building moves and comes to life. ${ }^{2}$

\section{Digital Dynamic Applications of Descriptive Geometry}

Anamorphosis represents an interesting field of investigation that includes numerous theoretical studies in both analytic-geometrical and graphical-geometrical keys.

The constructions proposed here explicate the potential of anamorphic procedures applied to a shape projected on plane, ruled or polyhedral surfaces by using dynamic geometry software such as Cabrì Géomètre and GeoGebra.

The use of these tools allowed us to strengthen the interaction between the theoretical-conceptual and figurative component in applications of descriptive geometry, deepening cultural and educational knowledge in the field of the science of representation. The commands allow us to analyze the intrinsic relations between geometric entities, through the manipulation (moving, rotations, enlargements) of control points during the constructions. Thus, it is possible to interactively validate

\footnotetext{
2 The realization of a 3D mapping project forecasts an advanced hardware/software equipment (3D modeling, liquid simulation, creation of special effects, high bright projectors) and takes advantage of knowledge that span different scientific fields.
} 
an initial hypothesis, and to presuppose and verify the properties and relations that remain unchanged or vary during geometrical transformations.

Compared to the traditional tools for drawing and CAD, the interactive and dynamic interface allows us to modify the mutual position of the constrained geometrical entities, setting up several case studies. Furthermore, we can highlight important and effective interactive procedures inside these software programs which are useful to comprehend the sequence of graphical operations that generate the geometrical shapes, such as step-by-step reproduction of graphical procedures, visualization of the construction protocol by means of the list of executed commands, and the construction of "geometrical loci" of points that satisfy determined conditions (Di Paola 2010).

\section{Anamorphosis on a Plane Surface}

The special technique of anamorphosis projection is described in many treatises of the period and the adopted procedure reverses the rules of central perspective (Baltrušaitis 1969). For example, the Italian Giovanni Paolo Lomazzo, in his treastise on art, painting, sculpture and architecture (1585), introduces concepts, definitions and classifications on the anamorphic dissertation, that remains until today. For example, he employs for the first time the term "inverse perspective", which indicates the singular geometric process that leads to represent the reality by deforming itself through a strict geometric projection. In fact, unlike what happens in the perspective method, the projecting rays depart from a point of view, go forward toward the real observed object and are ideally prolonged until they meet the wall surface on which the anamorphic representation will be performed. The

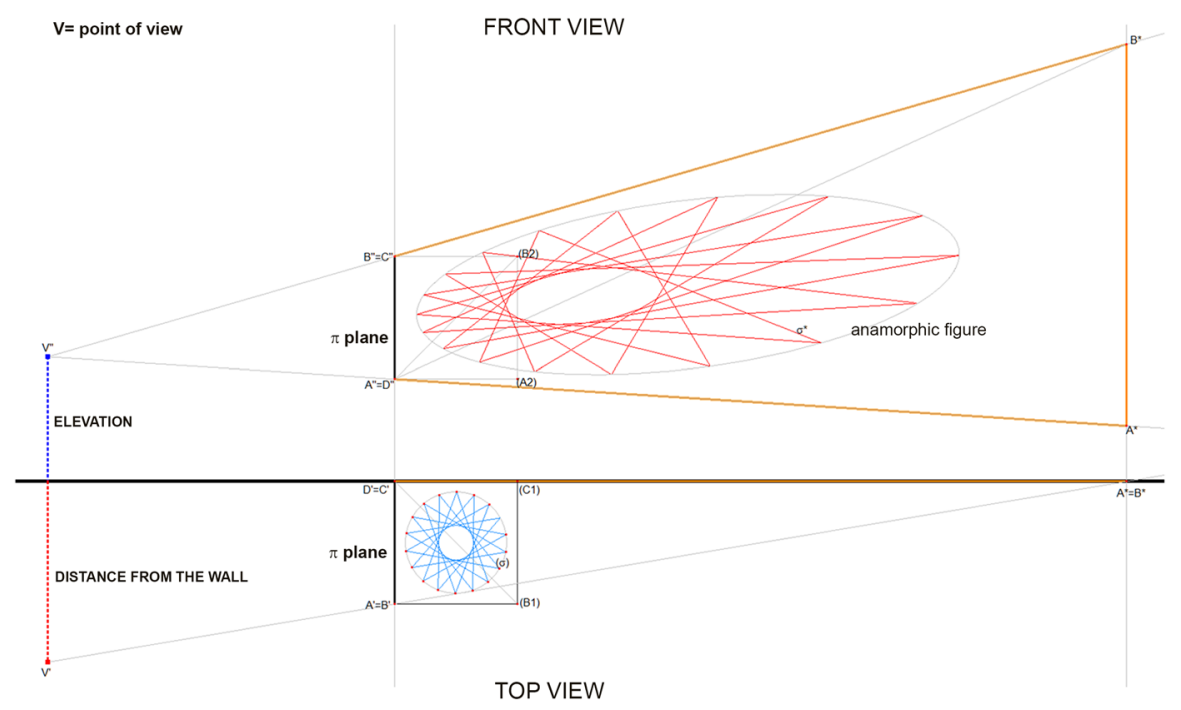

Fig. 17 Representation in double orthogonal projection of inverse prospective onto plane surface 


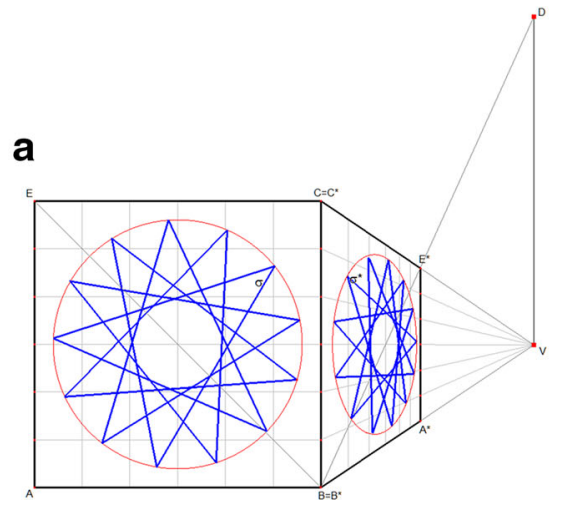

b

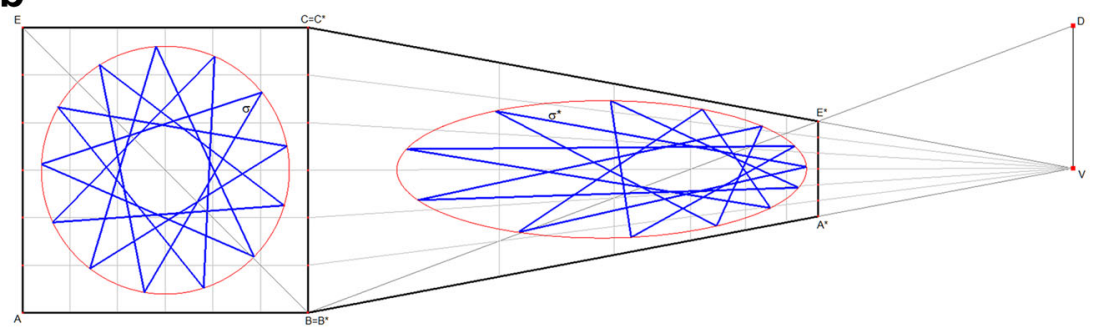

C

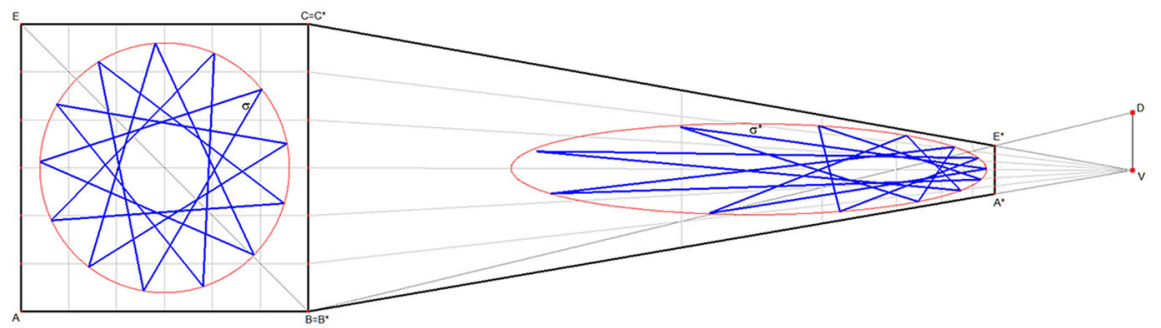

c.

Fig. 18 Anamorphosis carried out from a perspective distortion. Once the shape has been printed on a paper sheet, VD indicates the distance of $\mathrm{V}$ from the sheet to observe the image. By dynamically changing the positions of the points, it is possible to obtain different anamorphic deformations $(a, b, c)$

observation point is at a certain height from the floor and a certain distance from the wall (Fig. 17).

The shape in true form and dimension is represented on picture plane (in earlier times, gridded canvas was used), placed at a known distance from the observer, orthogonal to the wall surface. Once made, the anamorphic picture is in inverse perspective (by means of auxiliary tools such as taut wires that materialize the visual rays). In order to observe the drawing in the correct proportions, the observer must be positioned obliquely to the wall, placing himself in the same position of the point of view of construction. This optical phenomenon occurs because it materializes the picture projection that was ideally positioned where the painter 


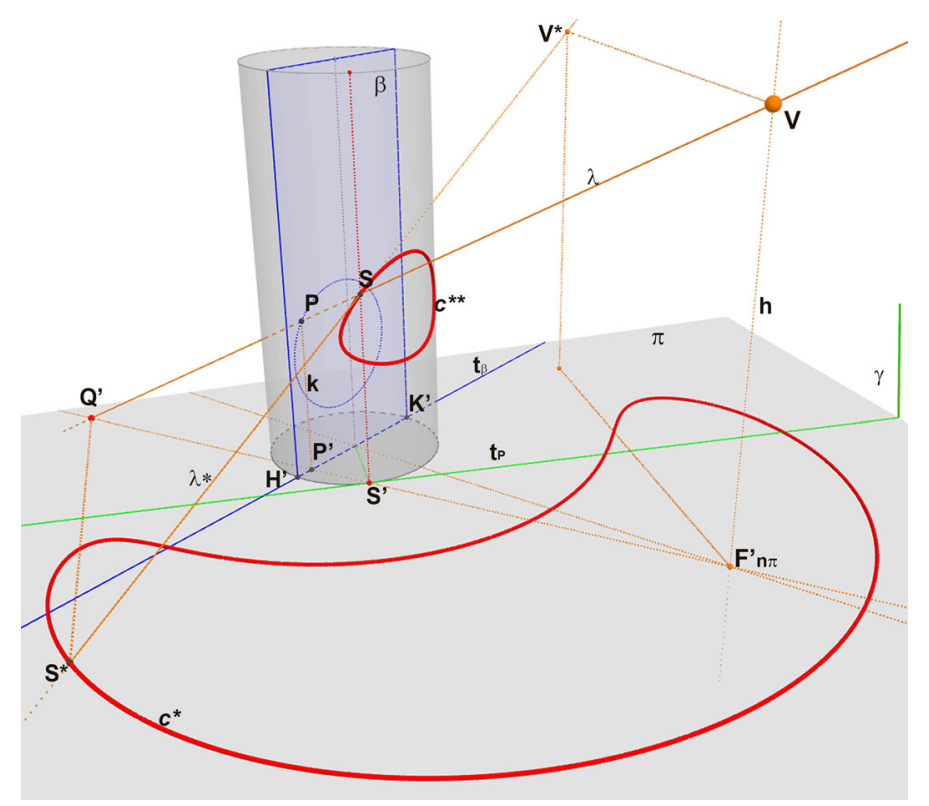

Fig. 19 Catoptric anamorphosis on a cylindrical ruled surface. Schematic perspective view of the geometric procedure of construction

had placed the drawing in true form before projecting it on the wall (Di Lazzaro and Murra 2013).

Obviously, when viewed from all other positions, the image will appear absolutely deformed. The geometric construction in Fig. 18, made in Cabrì, proposes the schematic setup of the inverse perspective; by dynamically changing the position of $\mathrm{V}$ (point of view) and $\mathrm{D}$ (which shows the distance of $\mathrm{V}$ to the surface) it is possible to observe different anamorphic deformations.

\section{Specular Anamorphosis on Cylindrical Ruled Surface}

The specular anamorphic projection of a shape on a reflecting surface follows the laws of reflections; in this case, we apply the geometrical procedure described above on a circular cylindrical specular surface with a right axis. Figure 19 shows the three-dimensional scheme that describes the phenomenon of catoptrics.

Given a cylinder whose height and diameter of the circular directrix are known, and which is placed on the horizontal picture plane $\pi$, we define $\mathrm{V}$ as the observer's point of view. We then represent an auxiliary vertical plane $\beta$ that contains the cylinder axis and whose direction is orthogonal to the picture plane $\pi$. On this plane $\beta$ we can trace a curve (a circle in the example). A physical model would consider a cylinder made of a highly reflective material and a chosen virtual curve. Having chosen a point $\mathrm{P}$ belonging to the assigned curve, we trace the visual ray $\lambda$ that connects $\mathrm{V}$ with $\mathrm{P}$ and intersects the cylinder in $\mathrm{S}$ and the picture plane in the virtual 


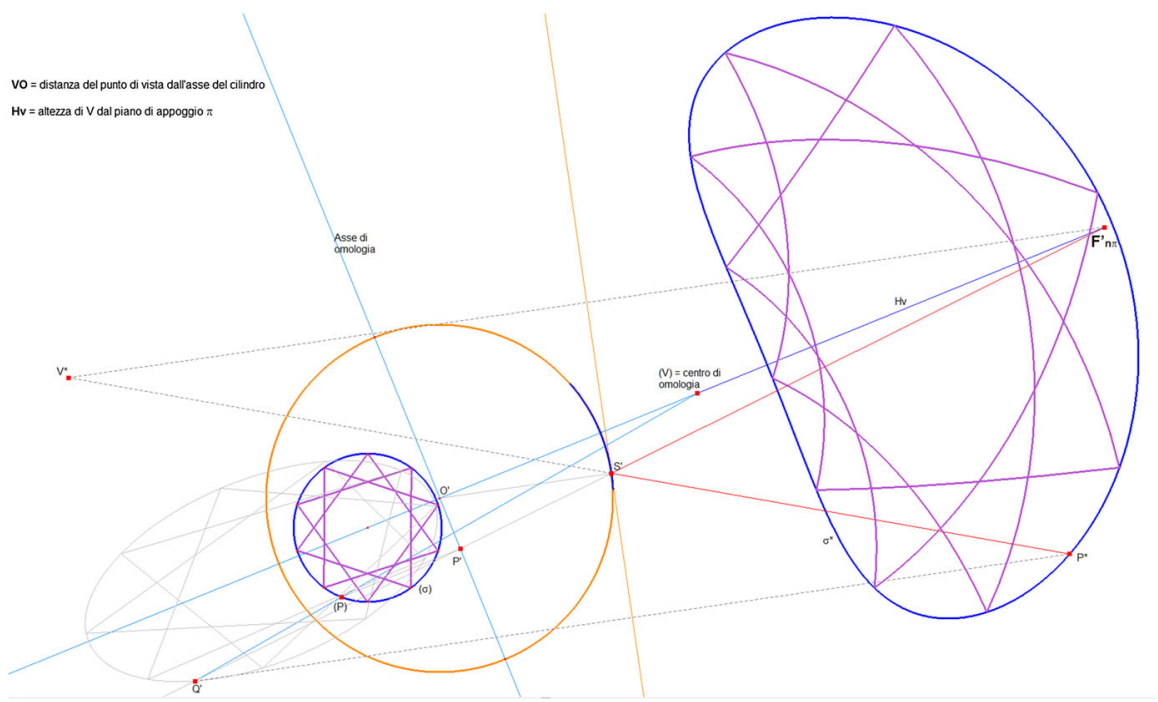

Fig. 20 Catoptric, or specular, anamorphosis of a star, enclosed in a circle, on cylindrical ruled surface; homological procedure

point $\mathrm{Q}^{\prime}$. From $\mathrm{S}^{\prime}$, projection of $\mathrm{S}$ on $\pi$, we draw the tangent to the cylinder directrix, $\mathrm{t}_{\mathrm{p}}$; this last is the trace of $\gamma$ vertical plane tangent to the cylinder and passing for $\mathrm{S}$.

According to the laws of reflections, the slope of the reflected ray $\lambda^{*}$ can be determined considering the point $\mathrm{V}^{*}$, symmetric of $\mathrm{V}$ respect to $\gamma$; the intersection of $\lambda *$ ray, $\mathrm{V} * \mathrm{~S}$, with picture plane determines $\mathrm{S} *$. We can observe that the straight lines that connect the points $\mathrm{VQ}^{\prime}$ and $\mathrm{V}^{*} \mathrm{~S}^{*}$ are symmetric in relation to $\gamma$ plane and their points of intersection with $\pi, \mathrm{Q}^{\prime}$ and $\mathrm{S}^{*}$, are in axial symmetry with respect to $\mathrm{t}_{\mathrm{p}}$. Furthermore, the rectangle triangles $\mathrm{VF}^{\prime}{ }_{n \pi} \mathrm{Q}^{\prime}$ and $\mathrm{PP}^{\prime} \mathrm{Q}^{\prime}$ are similar, hence we have the relation $\mathrm{h}: \mathrm{k}=\mathrm{F}_{n \pi}^{\prime} \mathrm{Q}^{\prime}: \mathrm{P}^{\prime} \mathrm{Q}^{\prime}$, where $\mathrm{F}_{\mathrm{n} \pi}^{\prime}$ is the vanishing point of the perpendicular straight lines respect to $\pi$ (Martinez et al. 2008). ${ }^{3}$

If we move $\mathrm{P}$ on the virtual circumference, it describes two geometrical loci: $\mathrm{c}^{*}$, which represents the anamorphic projection of the assigned curve and $\mathrm{c}^{* *}$, the skew curve belonging to the cylindrical surface. To see the curve without any distortion, the observer must look at the anamorphic curve reflected on the cylindrical mirror from $\mathrm{V}$, the point of view; thus, the virtual and the skew curve will overlap.

It is possible to construct the anamorphic curve directly on the picture plane $\pi$. It is sufficient to revolve the plane $\beta$ into the picture plane $\pi$ around the straight line $t_{\beta}$, determining the point $(\mathrm{P})$ and the point $(\mathrm{V})$, thus establishing an homology with center $(\mathrm{V})$, axis $\mathrm{t}_{\beta}$ and corresponding points $\mathrm{Q}^{\prime}(\mathrm{P})$. Given a point $\mathrm{P}$, it locates the point $\mathrm{P}^{\prime}$ orthogonally on $\pi$, and then, through homological construction, it determines $\mathrm{Q}^{\prime}$ and finally $\mathrm{S}^{*}$, through axial symmetry respect to $\mathrm{t}_{\mathrm{p}}$.

\footnotetext{
${ }^{3}$ Unlike our proposed method, the one used by seventeenth-century treatise writers is based on transformation theory: the drawing is divided into some square cells that give a system (in this case according to cylindrical symmetry) of distorted cells, up to becoming parts of a circular crown.
} 


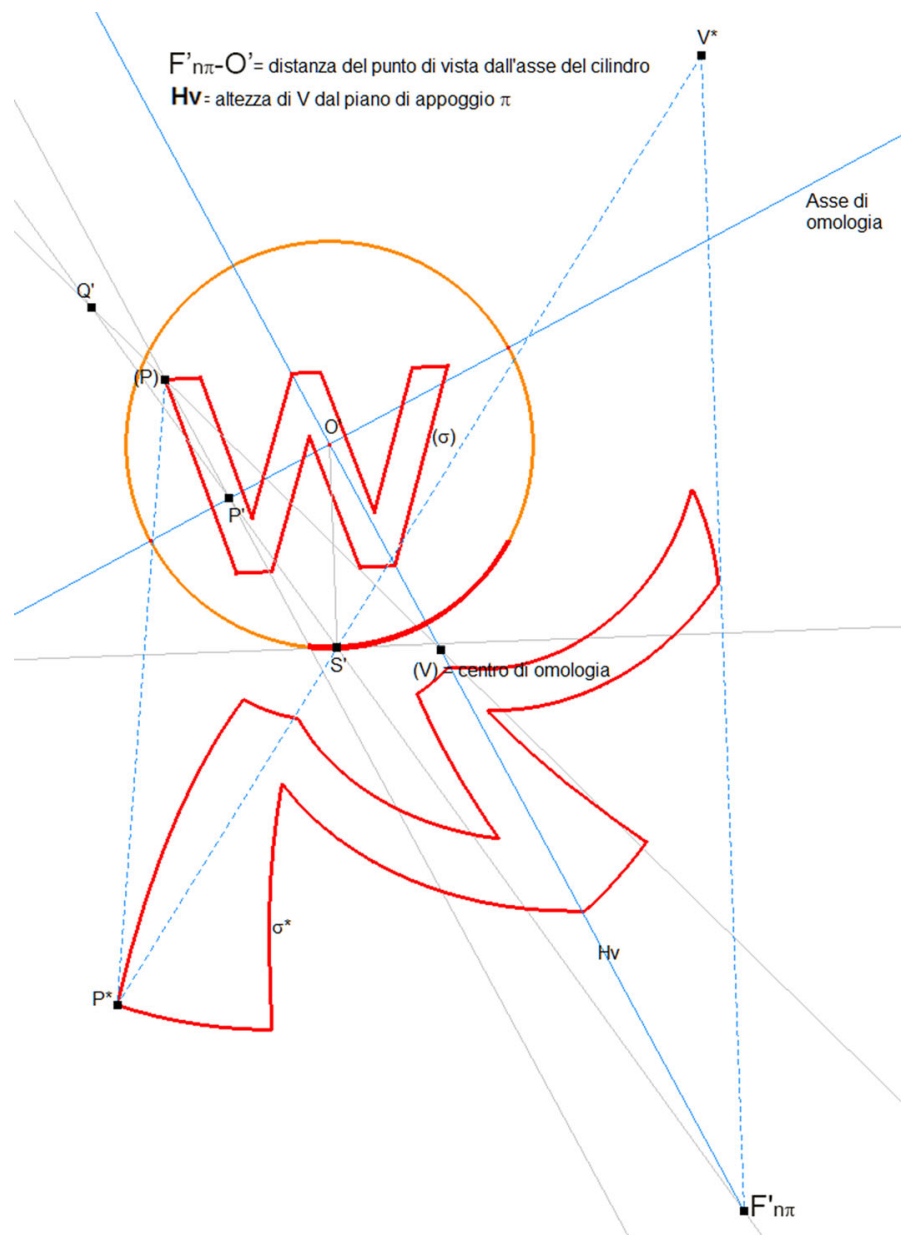

Fig. 21 Catoptric, or specular, anamorphosis of letter "W" on a cylindrical ruled surface; homological procedure

Figures 20 and 21 show two examples of specular anamorphic projection on the mirrored cylindrical surface carried out with homological methods; a stellated polygonal shape inscribed in a circle and a polygonal shape in the form of the letter "W".

\section{Applications of Anamorphosis in Descriptive Geometry}

\section{Anamorphosis in Perspective}

Let us analyze another example that describes the perspective projection in the vertical picture plane of an articulated room with vertical walls, inclined with respect to the picture plane (Figs. 22, 23). 


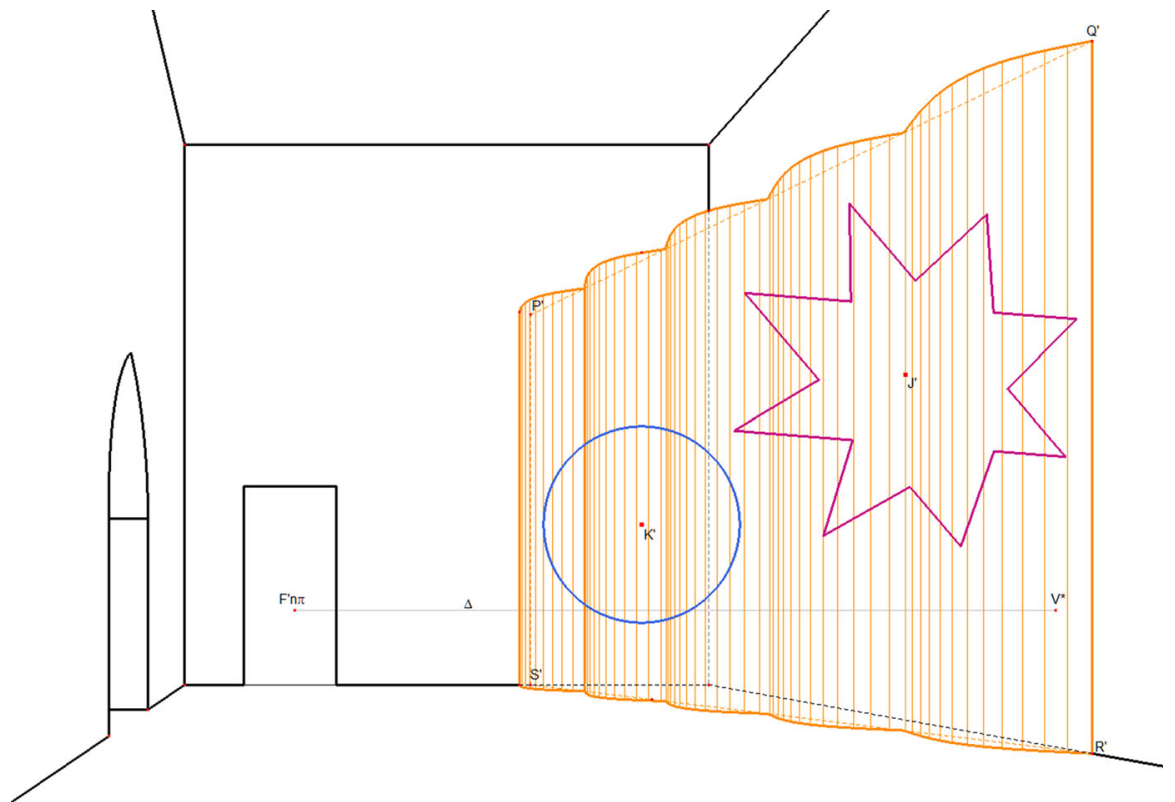

Fig. 22 Anamorphic projection in perspective of two geometrical figures on a cylindrical ruled surface with sinusoidal arches. The visual perception of the curves is misleading, as in reality these are very deformed

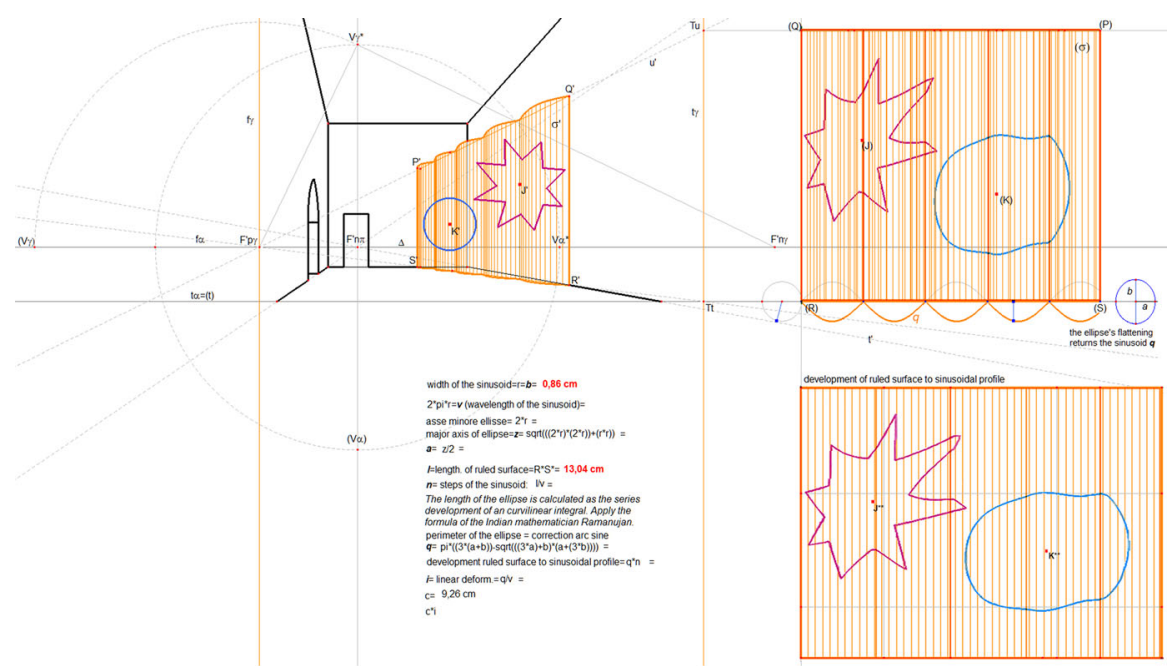

Fig. 23 Anamorphic projection in perspective; turning over on $\pi$ and development of the surface with sinusoidal arches; real form of projected anamorphic figures

We represent directly in projection two anamorphic figures (a eight-pointed star and a circle), perceived from the chosen point of view $\mathrm{V}$ in real shape (that is, not deformed) and belonging to a ruled surface $\sigma$. 
To construct this surface, we chose any vertical plane $\gamma$, turning over the outline $\mathrm{t}_{\gamma}$ on $\pi$; the generatrix $\mathrm{q}$ is determined by arranging sinusoidal arches in sequence along it. The surface is generated by a vertical line translated along the generatrix $q$. The surface and the plane are then turned over on $\pi$, resulting in the projection of the curves and of $\sigma$ on the plane $\gamma$. The ruled surface is developed on the plane $\gamma$ by determining true size and shape of the surface and the two anamorphic figures.

The distance $\Delta$ of $\mathrm{V}$ from the picture plane $\pi$, corresponds to the distance from $\mathrm{V}$ to $\mathrm{F}_{n \pi}$, where $\mathrm{F}_{\mathrm{n} \pi}$ is the vanishing point of the perpendicular straight lines to $\pi$ (Inzerillo 2008, 2012). The vertical oblique plan $\gamma$ is uniquely determined by marking the trace lines $t_{\gamma}$ and the vanishing lines $f_{\gamma}$. The ruled surface $q$, with amplitude and wavelength assigned, rests over $\gamma$.

In this paper, we leave out the description of the geometric-constructive steps that lead to the determination of the overturning of the wavy surface. It is observed that, for development of the surface, the known relationship between the length of the elliptic curve and the sine wave has been exploited.

The development of the latter curve is calculated using the formula of the Indian mathematician Ramanujan that determines with approximation the length of the ellipse as the development in series of an integral curvilinear (Villarino 2008).

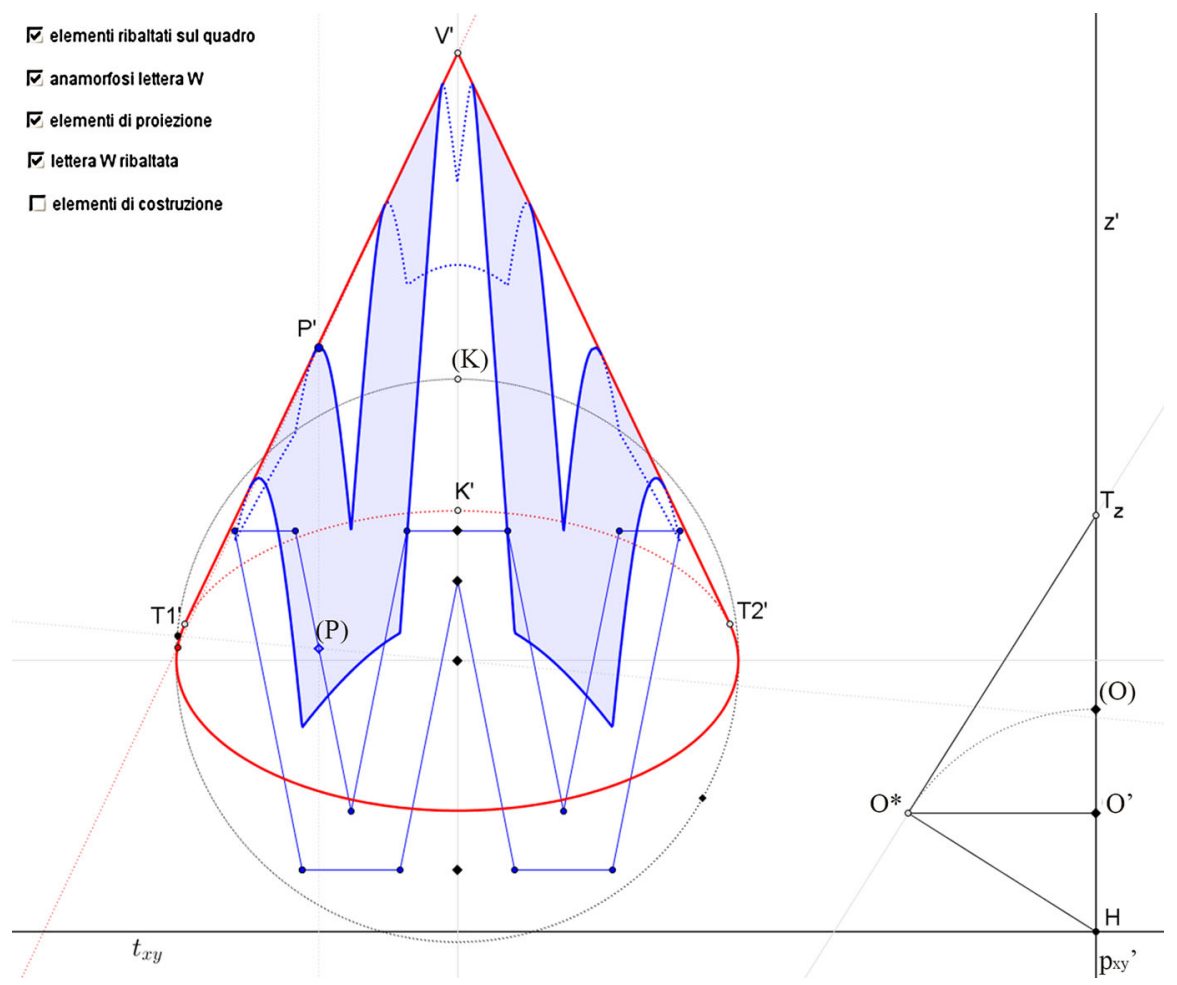

Fig. 24 Anamorphic projection in direct axonometric. Representation of a right circular cone placed on the xy coordinate plane; anamorphic projection of the letter " $W$ " on the ruled surface 

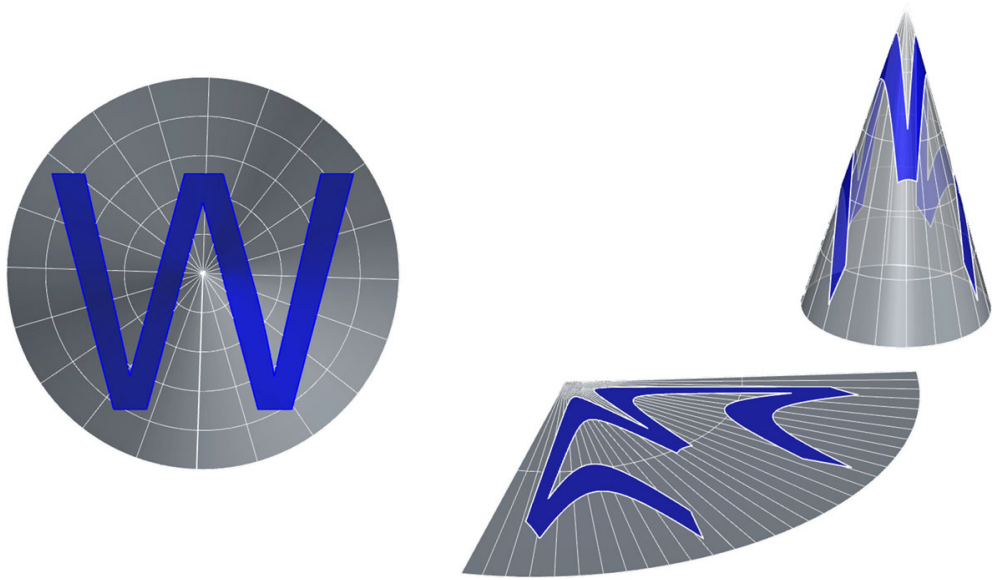

Fig. 25 Anamorphic projection of the letter " $W$ " on a conical surface; development onto the plane of ruled surface and true shape and size of the letter. On the left it shows the top view, on the right there is a perspective view of the model and its development

\section{Anamorphosis in Direct Axonometry}

The construction in direct orthogonal axonometric projection describes the representation of a right circular cone placed on the xy plane and the anamorphic projection of a polygonal "W" shape on the ruled surface (Figs. 24, 25).

In order to define the axonometric projection layout, we have to trace two orthogonal straight lines on the sheet: the $\mathrm{z}^{\prime}$ vertical straight line (projection on the picture plane of the $\mathrm{z}$ axis of the three-orthogonal triad) and the horizontal straight line as $t_{x y}$ (intersection of the xy plane with $\pi$ picture plane). Then on the $z^{\prime}$ axis we define $\mathrm{O}^{\prime}$ [projection of $\mathrm{O}$, the origin of $(\mathrm{x}, \mathrm{y}, \mathrm{z})$ triad, on $\pi$ picture plane] and (O) (turned over of $\mathrm{O}$ on the $\pi$ picture plane) by setting up an homological ratio $\mathrm{H}(\mathrm{O}) / \mathrm{HO}^{\prime}\left(\mathrm{H}\right.$ is the intersection between $\mathrm{xy}$ maximum slope straight line and $\mathrm{t}_{\mathrm{xy}}$ ) (Inzerillo 2012: 50-55). When we turn over the xy plane on the picture plane we establish an affine orthogonal homology whose center is at infinity in the direction $\mathrm{O}^{\prime}(\mathrm{O})$, the axis is the straight line $\mathrm{t}_{\mathrm{xy}}$ and a pair of corresponding points is $\mathrm{O}^{\prime}(\mathrm{O})$. Once the cone is built (Inzerillo 2012: pp 69-73), the anamorphic letter is obtained by drawing, on the overturned plane, the real shape and size of the letter (in our example, a W), in a position that it is inside the cone directrix. Choosing a point $\mathrm{P}$ on the letter, we find $(\mathrm{P})$ on the overturned xy plane, then we trace the generatrix of the cone where $(\mathrm{P})$ lies and, following homological procedures, we find the corresponding generatrix of the cone in projection and the corresponding point $\mathrm{P}^{\prime}$. In GeoGebra, the anamorphic letter on the ruled surface is determined by the geometrical locus described by point $\mathrm{P}^{\prime}$ according to its constraint to $\mathrm{P}^{*}$.

\section{Anamorphic Curve by Two Projection Views}

The following example shows an anamorphic mixtilinear three-dimensional curve, which is not readable when viewed as a three-dimensional object; instead it is 
TOP VIEW

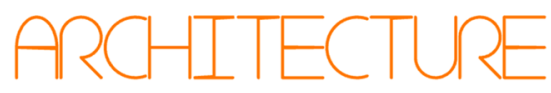

FRONT VIEW
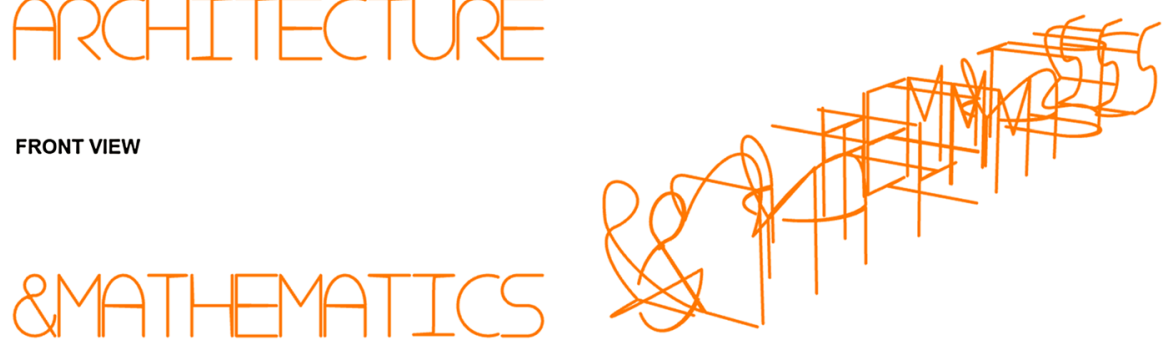

Fig. 26 Anamorphic curve produced by two plane curves in different construction plans. The set of both original curves is not readable when viewed as a three-dimensional object, but only as two projected views (top and front)

necessary to observe it from two different projection views (in our example, front and top view), so that the curve reproduces two scripts: "architecture" and "\& mathematics" (Fig. 26). ${ }^{4}$

\section{Anamorphic Curves in Freeform Architecture}

It is now common practice in contemporary architecture to design and construct buildings whose architectural expression relies on complex forms. The implementation of the initial concept can be carried out by two methods: (1) by using continuous curve surfaces, described by mathematical function (NURBS, NonUniform Rational B-Splines), and executing them as either a single solution or as a composition of several panels suitably molded (according to the characteristics of the material used); (2) by using "polygon mesh" polyhedral surfaces, composed of small polygonal plane faces that contribute, to the definition of a variously articulated form (Wallner and Pottmann 2011).

The purpose of the present study is to examine the design and execution of curves on freeform surfaces in cases where these are meant to be observed from a specific point of view. Knowing the geometric properties of the surfaces-type and class, curvature evolution, apparent contour, architectural genesis-is of crucial importance, given the generically complex evolution of the shells, for both architectural feasibility and aesthetic output. In what follows we will describe several case studies of applications of anamorphic curves on complex shells of contemporary architecture (Figs. 27, 28, 29).

For some years now a convergence of diverse sectors has resulted in a new field of study called "architectural geometry" (Pottmann et al. 2007). This discipline

\footnotetext{
${ }^{4}$ The algorithm used exists in the command set "Tools curve" within the work environment of the software Rhinoceros. The command "curve from two views" creates a third curve from two planar curves in different construction plans. The new curve is the same as both curves when viewed from their original construction plans.
} 

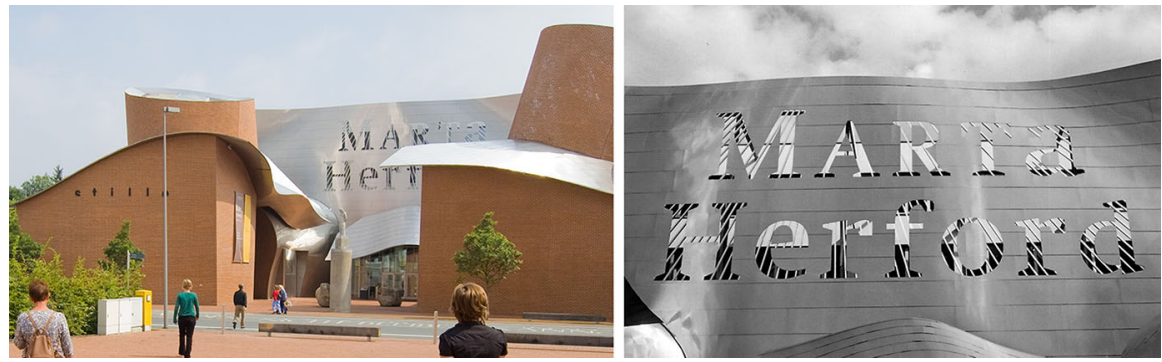

Fig. 27 Marta Herford Museum (Frank O. Gehry, 2001-2005): photo of the entry sign, made by drilling the freeform metal surface; picture of the surface structure. (Right) Author: Denis Defreyne, licenza Creative Commons Attribution 2.0. https://creativecommons.org/licenses/by/2.0/legalcode. No change to the figure: https://flic.kr/p/cJDpM. (Left) Author: Arne Kösel, licenza Creative Commons AttributionShareAlike 2.0 Generic https://creativecommons.org/licenses/by-sa/2.0/legalcode. No change to the figure: https://flic.kr/p/2Du55e
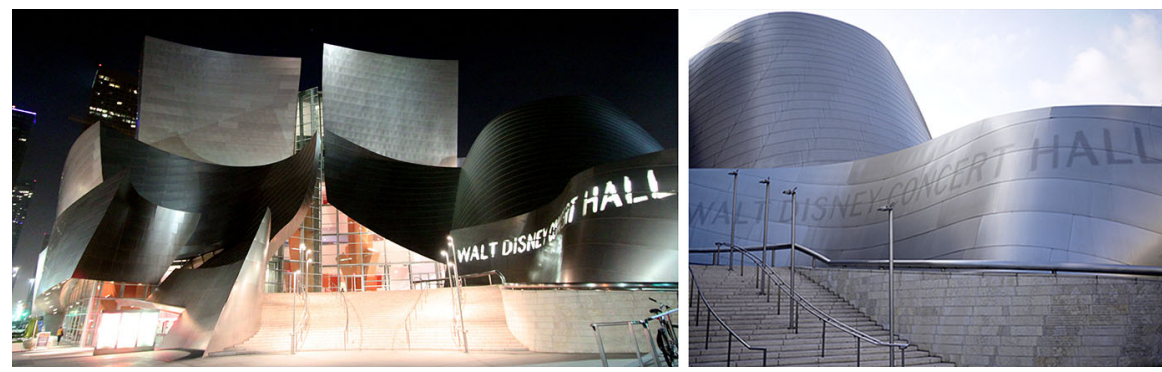

Fig. 28 Walt Disney Concert Hall (Frank O. Gehry, 1987-2003): building overview and pictures of the backlit entry sign, made by drilling the freeform surface. (Left) Autore: Prayitno, licenza Creative Commons Attribution 2.0 Generic. https://creativecommons.org/licenses/by/2.0/legalcode. No change to the figure: https://flic.kr/p/gXeQFf. (Right) Author: Adam Noce, by author's courtesy: https://flic.kr/p/ 8zunM1

involves all those aspects concerning complex geometries used in designing and constructing buildings. The panelling of complex surfaces is one of the hottest topics in architectural geometry. According to a classification of the major trends (Tonelli 2012), there are two discretisation methods. The first, based on polygonal plane panels comprises, among others: triangular meshes (which, however, show issues related to an high number of links, resulting in a heavy structure, and in case of glazed areas, a reduced transparency), quadrilateral meshes (which simplify and lighten the structure, but do not automatically guarantee the panels' flatness, requiring a finishing of the calculations methods) and hexagonal and polygonal hybrid meshes (generated by even more complex algorithms). The second method is based on ruled surfaces, and involves the acquisition of concept surfaces and a consequent geometric analysis, aimed at a possible approximation with a set of straight lines, which would make it possible to create portions of concept surfaces using ruled surfaces (Flöry and Pottmann 2010; Eigensatz et al. 2010).

The polysurfaces illustrated here have been chosen and then realized taking as a model well-known buildings, already realized or currently in progress, which show 

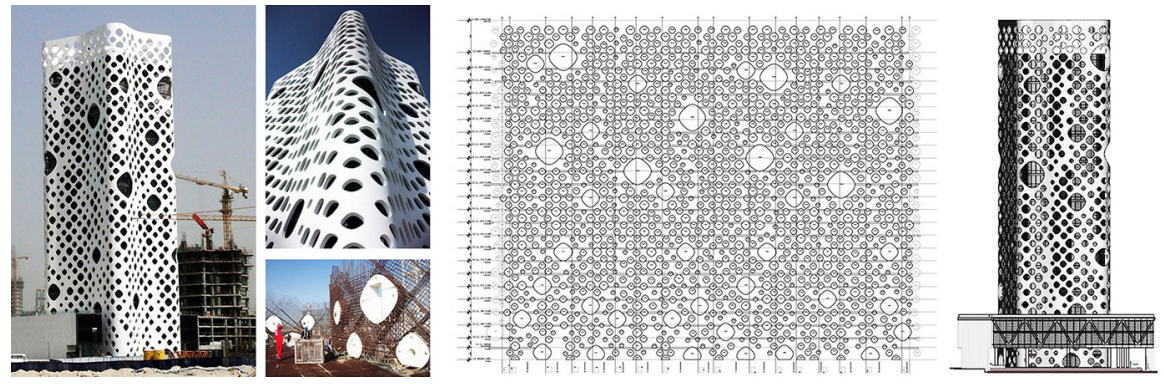

Fig. 29 O-14 (Reiser + Umemoto, 2007-2009): the exoskeleton, made of superfluid reinforced concrete, required hard work to be designed especially during the formwork and reinforcement design. (right and center) http://www.contemporist.com/2011/03/10/o-14-tower-by-reiser-umemoto/. (Left) http://www.reiser-umemoto.com, http://www.ngphoto.com.pt

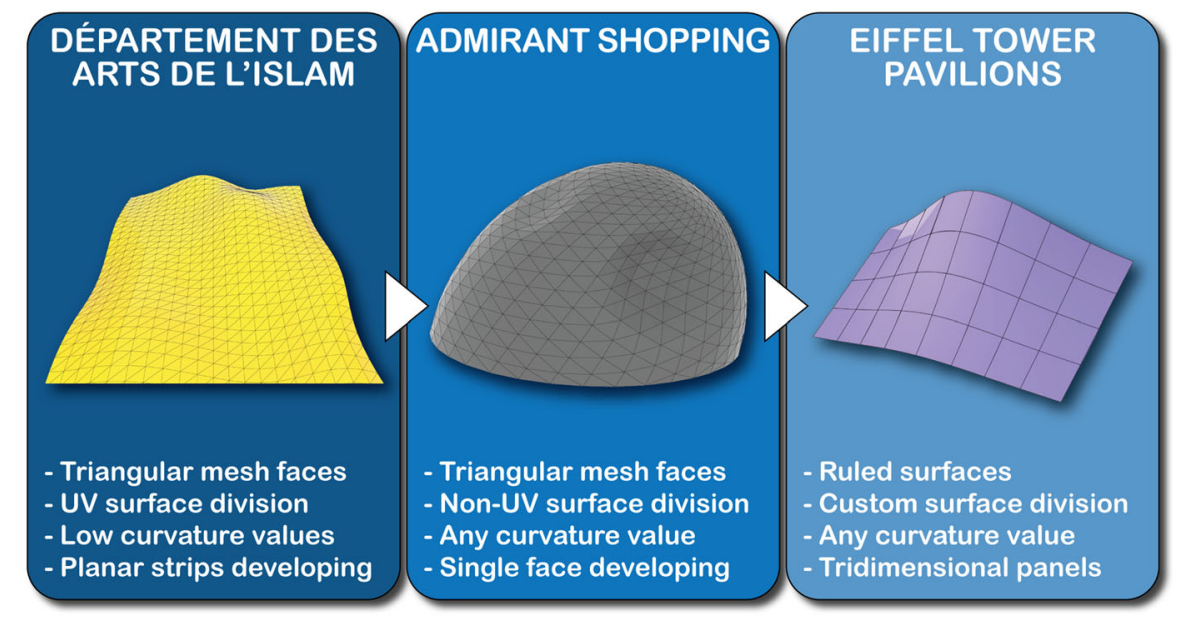

Fig. 30 Case studies: the examples were based on structures of the last decade already built or to be built

peculiar forms and geometric-spatial complexities in accordance with the present research. The polyhedral surfaces considered as models for the case studies presented here are the ondulating roof of the Department of Islamic Arts of the Louvre Museum in Paris, Admirant Shopping in Eindhoven, and a study for the freeform glass pavilions of the Eiffel Tower in Paris (Fig. 30).

The case studies that appear here show the anamorphic curve as if it were meant to be perceived from a privileged point of view, such as a raised platform, a nearby building or a specific position below the roof. Curves may represent signs, used to identify the building or some of its portions, passage openings or skylights, or even for decoration. ${ }^{5}$

\footnotetext{
5 Our ongoing research also deals with the definition of the necessary procedures for texture anamorphism, a matter not treated here but which will be the subject of further developments.
} 
While in applications of regular anamorphosis, discussed earlier, the figures were reproduced on flat surfaces or, at least, on surfaces with well-known characteristics, such as small-scale cones and cylinders, applications in contemporary architecture presuppose other dimensions and surfaces, with different levels of geometrical complexity. Even in cases of polyhedral surfaces, the high number of attitudes may necessitate a laborious procedure for creating the anamorphic images through the use of standard methods, given that would be necessary to deal with each element separately depending on the attitude of the projection plane. In these cases it is essential to use procedures that allow the greatest possible degree of automation in the process of creating the projected images, while also making interactive singleelement interrogation possible during each phase of design: this purely graphicgeometrical approach requires procedural generative algorithms in Rhinoceros environment through Grasshopper plug-in for visual programming. This plug-in makes it possible to generate a workflow by linking several components allowing input data elaboration through geometrical, mathematical or Boolean processes, typical of mesh and NURBS modeling. It also allows data interrogation for an accurate verification of their geometrical properties (curvature, continuity, etc.). The general procedure involved the acquisition of a concept surface and its panelization by the two most popular methods used by architecture professionals (Tonelli 2012): discretization by polyhedral polysurfaces, composed of triangular faces, and approximation by surfaces with known geometrical properties and simple geometrical genesis.

Case Study 1: Projection on a Freeform Surface Divided into Triangles Along the uv Directions

Our first case study shows a generic NURBS as base surface which follows the ondulated roof's lines of the Louvre Museum's Department of Islamic Arts in Paris, Italian architect Mario Bellini with French architect Rudy Ricciotti (Fig. 31). This roof is made of a free form layer of flat glass panels positioned below a polyhedral screen surface, which is composed exclusively of triangular faces: its footprint is rectangular, which allows a division in nearly-square sectors along the uvdirections, each of them composed of two triangles, and for a consequent
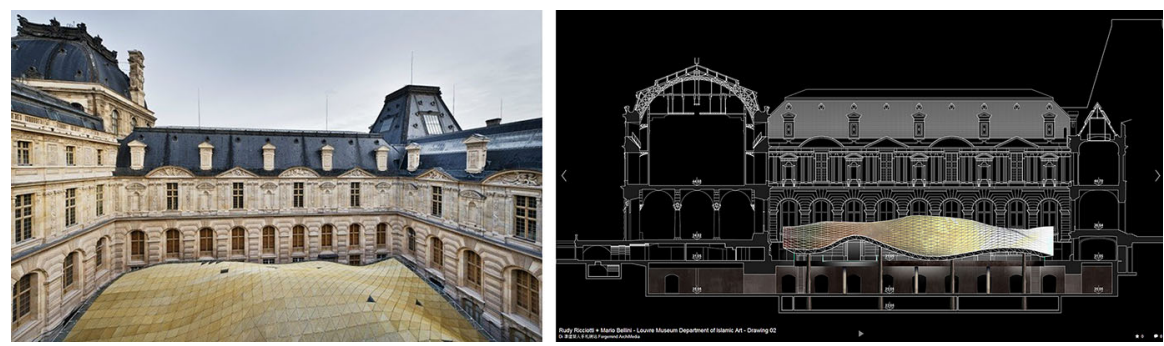

Fig. 31 Case study 1: The Department of Islamic Arts, Paris, photos of the ondulated roof. http://www. rudyricciotti.com/ 

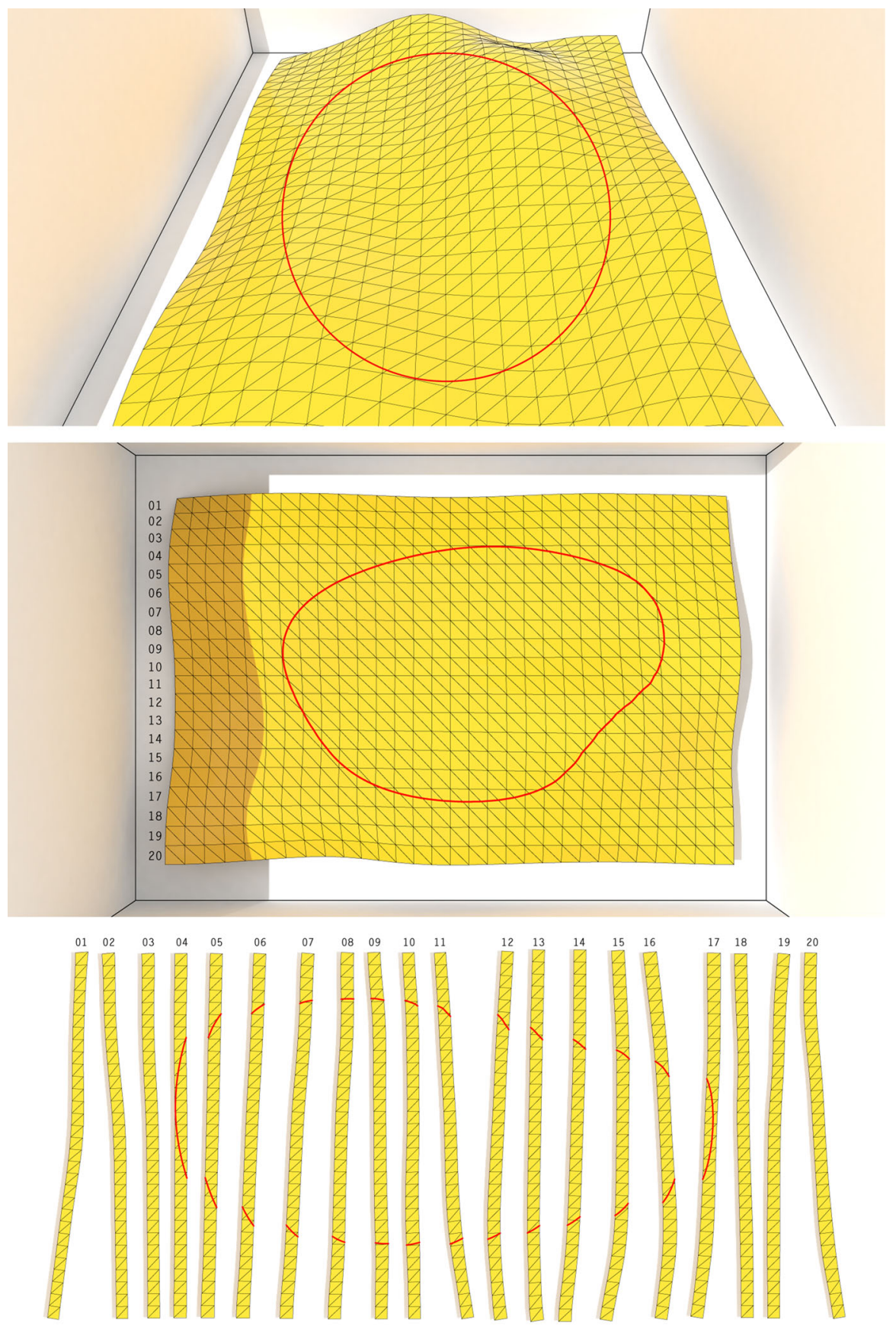

Fig. 32 Case study 1: freeform surface projection divided in triangles along the UV directions. The model follows the evolution of the polysurface designed by Ricciotti and Bellini, showing an anamorphic curve projected from a raised point; below, the development of strips with reference to the curve's segments 


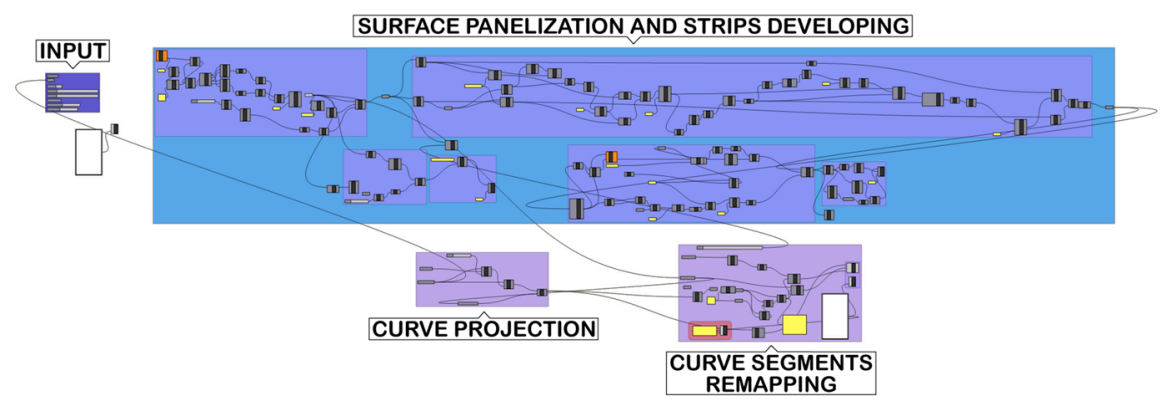

Fig. 33 Case study 1: operating scheme of the Grasshopper algorithm
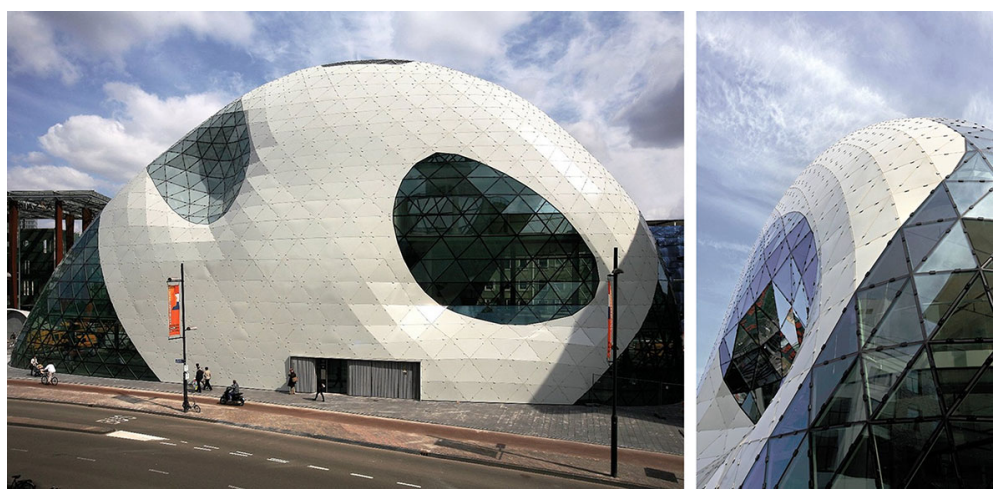

Fig. 34 Case study 2: Admirant Shopping, Eindhoven, photos of the building and details. (Left) author: Ken Lee, by author's courtesy: https://flic.kr/p/cZFE1S. (Right) author: Ken Lee, by author's courtesy: https://flic.kr/p/cZFDVd

development of the panels along strips, according to the "triangulated surface strip tool" (Heumann 2011) (Fig. 32). The anamorphic curve is then projected on the resulting polysurface from the preferential point of view (in this case: from a window of one of the galleries): the intersections on the three-dimensional model are remapped on the corresponding faces developed on the flat strips.

Each triangular face is connected to the curve segment, if there is one, projected on it: thus is possible to send necessary information regarding the layout of these curves to those responsible for panel manufacturing (Fig. 33).

\section{Case Study 2: Projection on a Freeform Surface Anyhow Divided in Triangles}

Case study 2 also shows a triangular element panelization, but uses Admirant Shopping in Eindhoven as a reference, designed by architect Massimiliano Fuksas (Fig. 34). The global form of this building did not allow us to use the previous approach, as the uv-directions of its surface do not form a structure easily divisible into strips. In our case study it was simplified as a mesh ellipsoid, then thickened with triangular faces using the Weaverbird approximation algorithm (Piacentino 

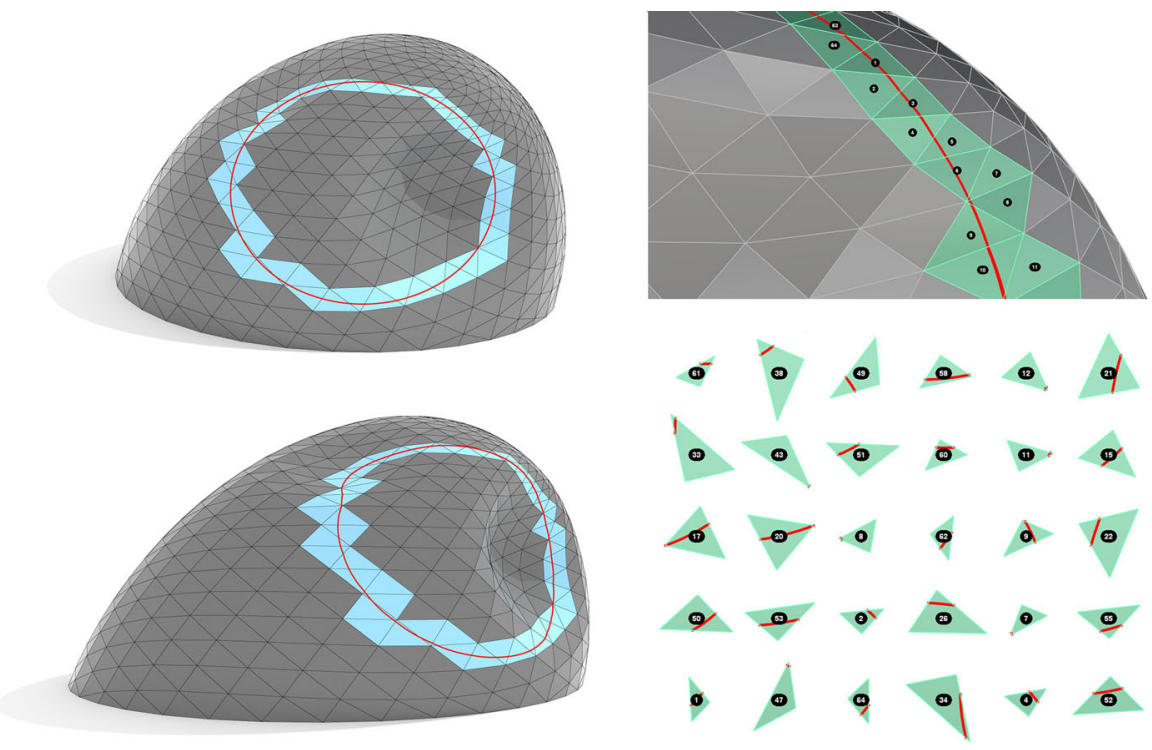

Fig. 35 Case study 2: freeform surface projection divided in triangles. Surfaces affected by the anamorphic curve's projection are highlighted in blue in the model; they are then numbered and positioned on a horizontal reference plane

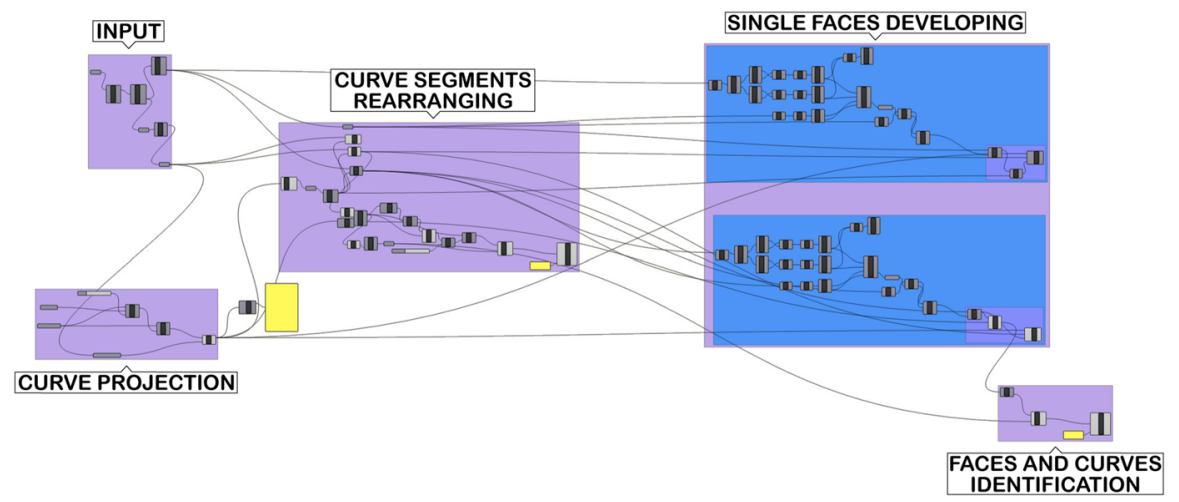

Fig. 36 Case study 2: operating scheme of the Grasshopper algorithm

2013), and, by modifying the positions of the control points, an irregular polysurface was generated, in order to retrace the building's line.

In this more generic case, it was preferable to proceed with the projection of the curve on the surface from a preferential point of view, and extracting from the mesh exclusively the information relative to the faces involved by the projected curves, converting them in polysurfaces (Fig. 35). Facesand curve segments were then linked and numbered progressively; all the necessary information for manufacturing is available at any moment thanks to the structured algorithm (Fig. 36). 


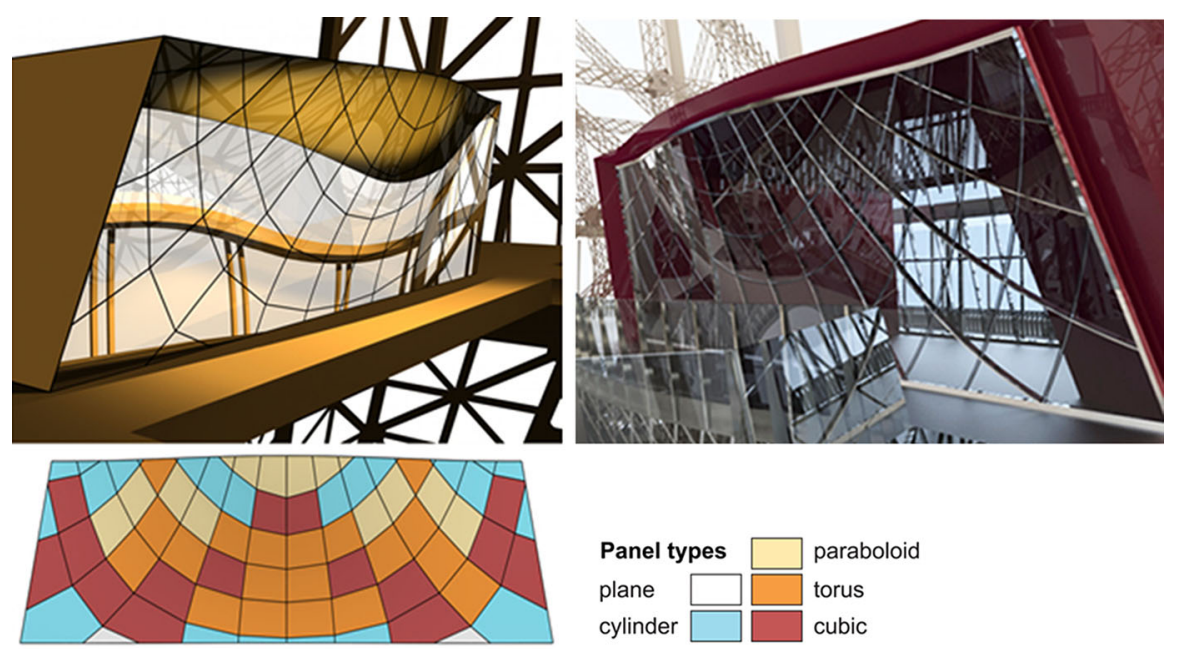

Fig. 37 Eiffel Tower pavilions by Eigensatz and Schiftner: (above) panel reflection and refraction study and project rendering; (below) a scheme showing the kind of the panels used. http://www.glassonweb. com/articles/article/765, support@evolute.at

Case Study 3: Projection on a Surface Approximated by Portions of Double-Curved Surfaces

The preliminary design can feature, as a concept, a NURBS surface to be made either of materials with a certain level of reflectivity (such as a metal or opaque glass cladding) or with transparent materials, showing refraction phenomena. If the surface is particularly extended or complex, it is extremely expensive or even impossible to manufacture it as a single piece; instead, applying one of the methods previously described, approximating it to a polyhedral surface, can produce an unsatisfactory overall outcome, thanks to the different directions of the normals to the faces (Baglioni 2012). In fact, the surface would show discontinuous reflection and refraction phenomena, quite different from the outcome predicted by the designer (Pottmann et al. 2008).

A feasible method to obtain a surface with characteristics similar to those of the initial concept is the one demonstrated in "Paneling the Eiffel Tower Pavilion" (Eigensatz 2012) and illustrated here (Fig. 37). The initial surface is divided following a network of plane curves, specified during the design phase, in panels with various shapes and with dimensions appropriate for manufacturing (symmetries, if any, from the original surface facilitate the work); each panel thus is analyzed separately, in order to find the best approximating surface with known geometry. In our case study the comparison was carried out using two families of ruled surfaces and one of revolution: hyperbolic paraboloid, right elliptic conoid, and torus (Eigensatz et al. 2010).

To use double-curved surfaces, a preliminary analysis is essential in order to identify any critical issues inherent in the surface geometry and predict the level of approximation: in particular, it is quite profitable to proceed with the determination 

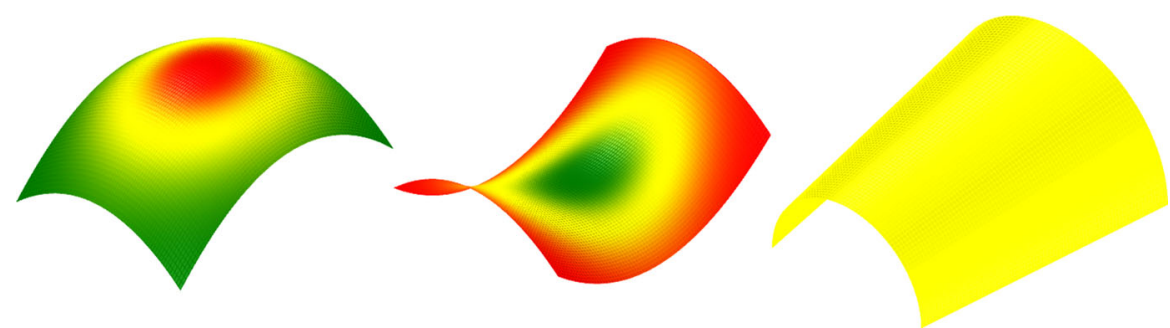

Fig. 38 Surfaces with different curvature values: from left to right, positive, negative and zero curvature (ruled surface)

of the surface's Gaussian curvature. This is defined locally as the product of the maximum and minimum values of curvature at a given point (these are determined through an operation of surface dissection made by a set of planes passing through the normal of the surface at that point, and then considering the maximum and minimum values of curvature of the section curves) and gives information about the local nature of the surface (Fig. 38). ${ }^{6}$

The NURBS surface to be analyzed, in Rhinoceros environment, is imported in Grasshopper and compared with the known surface through an evolutionary approach, made possible by the Galapagos component, by David Rutten. It uses a sequence of numerical sliders as input, the "gene pool": each slider describes a certain value related to the comparison surface, such as the coordinates of the vertices of the hyperbolic paraboloid or the radii of the torus; an addition three sliders present on each surface describe its angle of revolution around the three coordinate axes, in order to maximize the chances for a better correspondence. In other words, the sliders describe an $n$-dimensional "landscape", where $n$ is the number of the "genes" in the gene pool. The component is also linked to an output value, the "fitness", dependent on the sliders, which can be maximized or minimized depending on the purpose of the evolutionary simulation. For the case study at hand, the surfaces, obtained bycutting of the original NURBS, were compared to the approximation surfaces, calculating, through a high number of samples, the mean deviation: this value was used as the fitness of the component and prearranged for minimization. The evolutionary approach initially entails the attribution of a random sequence of values to the sliders, which will generate certain values of fitness. The the determination of the initial values is followed by a sequence of iterations (so-called "generations") resulting in an elimination of those combinations different from the desired outcome and the selection of the best ones, which are cross-referenced for the following generation. The output values of the "sons" are contained in the range of the values of the "parents", thus approaching the best possible value (Fig. 39).

The task, however, may not allow a unique solution or any solution at all. It is possible to establish some regulation values which will halt the simulation,

\footnotetext{
${ }^{6}$ In particular, the ruled surfaces have a curvature value equal to zero on each of their points, given that it is always possible to determine a direction where the section is a straight line -in other words, where the osculator circle has infinite radius, thus the curve has a null curvature.
} 


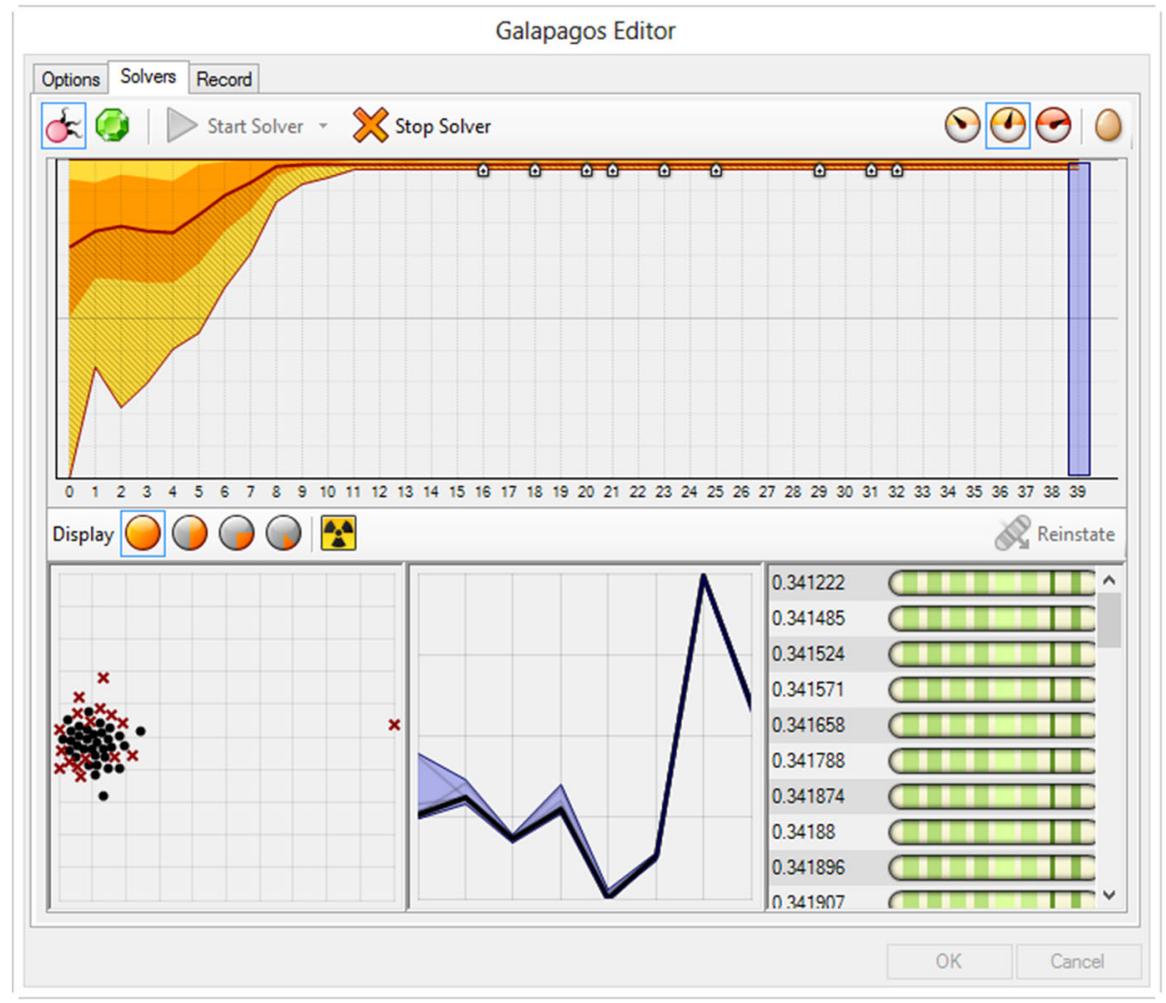

Fig. 39 Case study 3: routine example in Galapagos: as the generations progress, the fitness values are included in a smaller range (showing an ever-decreasing thickness of the yellow diagram)

deciding, for example, that it must stop when the values found from a generation to the next differ by a certain percentage from the "parent" values after a certain number of iterations; the only limitation to this approach is the calculator's computing capacities.

For our case study 3, we carried out a comparison between the three chosen surfaces (hyperbolic paraboloid, right elliptic conoid, and torus), considering the one that would best adapt to the given surface (Fig. 40).

Regarding the input panels, showing a range of surfaces of between 5,000 and $6,500 \mathrm{~cm}^{2}$, we determined, in the best cases, a deviation between the concept NURBS and the approximating one with a maximum of $0.2 \mathrm{~cm}$ and a nearly-zero minimum, and a mean deviation on the panel's edge of $0.1 \mathrm{~cm}$, with a maximum of $0.2 \mathrm{~cm}$ and a nearly-zero minimum. As an additional control method, we carried out an accurate analysis of the deviation of the surfaces extended over the entire panel, which allowed a prompt visual feedback of the portions that showed a greater or smaller deviation compared to the concept (Figs. 41, 42).

In this case there is no surface development, but the information about the projected curve is transmitted together with the properties of the approximating 


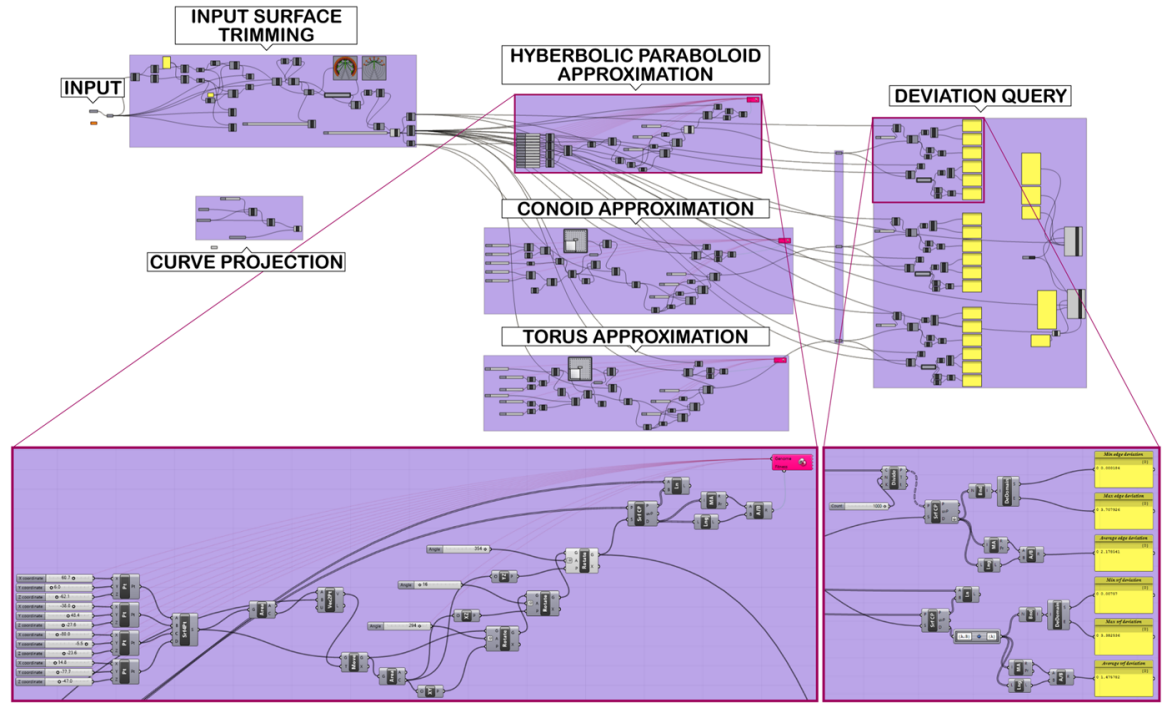

Fig. 40 Case study 3: operating scheme of the Grasshopper algorithm; detail of the hyperbolic paraboloid's approximation algorithm showing the Galapagos component in the upper right corner; detail of the query algorithm for the surfaces deviation
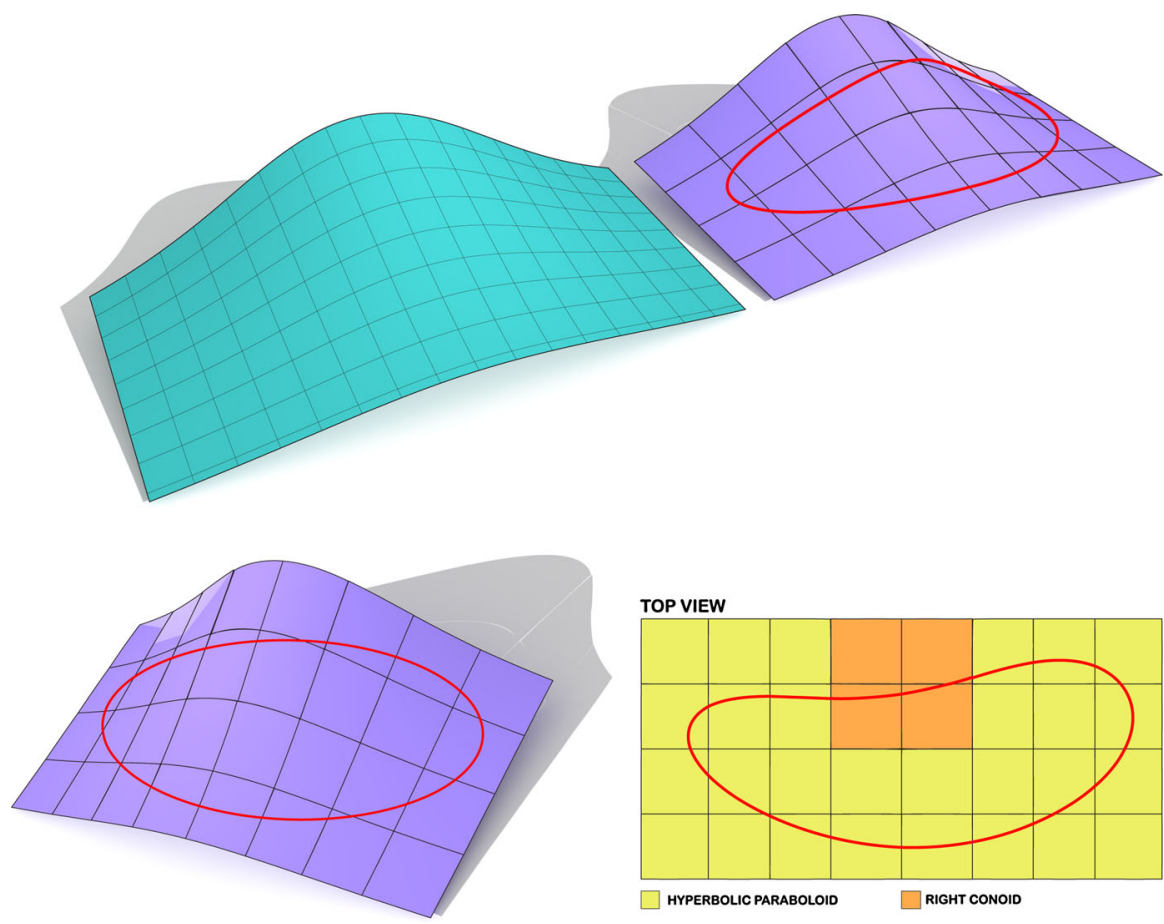

Fig. 41 Case study 3: projection on an approximated surface with double curved surfaces: (above) NURBS input surface and outcome of the approximation operations; (below) anamorphic curve (ellipse) reproduced on the surface portions and scheme of the panels' geometry 

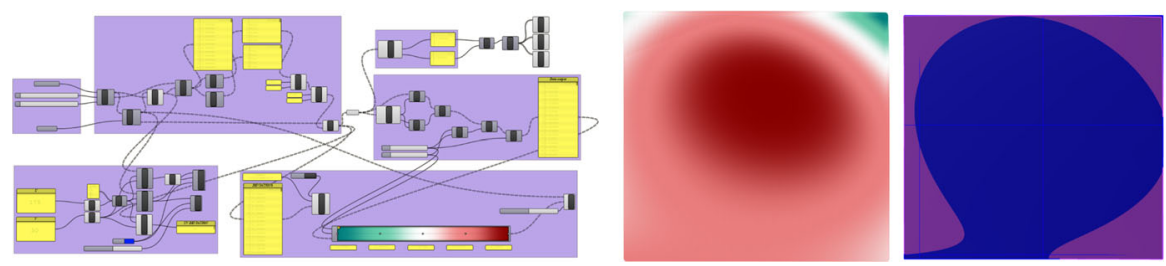

Fig. 42 Case study 3: (left) comparison algorithm and (center and far right) visual representation of the deviation between one panel of the concept NURBS surface (blue) and its approximating ruled surface (purple): points with positive deviation are shown in dark red, zero or nearly-zero in pink and negative in turquoise

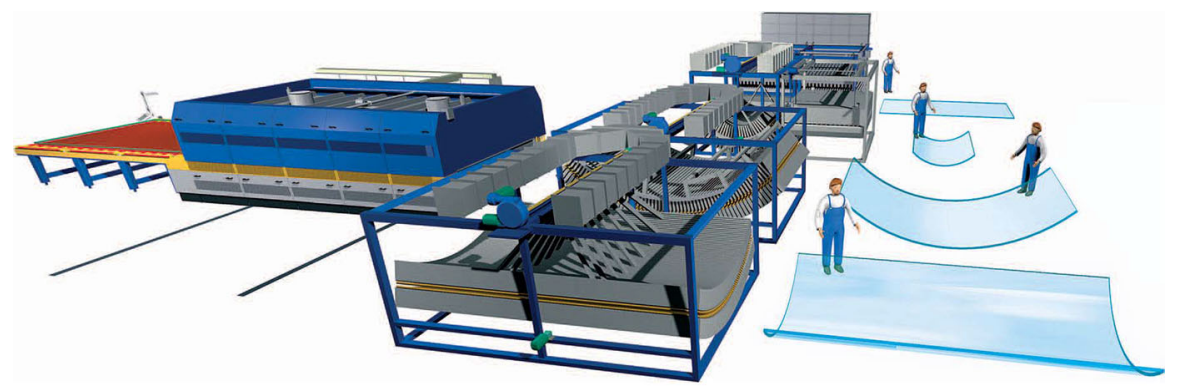

Fig. 43 Case study 3: diagram of CNC machinery used for glass panels production made by ruled portions (in the example, cylindrical surfaces), http://www.glaston.net/

surface, which can be manufactured directly as three-dimensional panels by CNC machineries through various processes (hot/cold bending, rolling, etc.) (Fig. 43).

\section{Conclusions and Future Work}

Our study has more deeply developed techniques for digital anamorphic projection. The different case studies led us to unexpected and surprising results: we demonstrated that the application of anamorphic principles onto complex architectural surfaces has been slimmed down and facilitated by using digital techniques and procedural algorithms.

The "3D architectural mapping" technique, among the applications most used today, provides evidence that anamorphic projections constitute one of the new frontiers in multimedia communication.

The graphical determination of reflected anamorphic images according to methods of descriptive geometry is an attractive field of research open to new exploration, particularly in the presence of different types of quadric surfaces: furthermore, the anamorphic projection of forms and shapes onto free-form complex surfaces is a very important topic in architectural geometry, as part of more general issues relating to the monitoring, investigation and analysis by means of geometric computer modelers. 
The case studies of anamorphic curves we have proposed were suggested by real situations of architectural building elements with complex covering surfaces. By using the methodology explained here it is possible to achieve a balance between the costs of execution and the geometrical-formal adherence to the design model. Future developments of our research will aim at refining the design of algorithms useful for optimizing the production process with CNC systems, and we plan to deepen our knowledge of this topic by cooperating with specialized companies in the field.

\section{References}

Accolti, Pietro. 1625. Lo inganno degli occhi: Firenze (free e-book. http://www.books.google.com).

Baglioni, Leonardo. 2012. I poliedri e le tecniche di tassellazione delle superfici continue: un nuovo punto di incontro. In: Attualità della Geometria Descrittiva, eds. Carlevaris Laura, De Carlo Laura, Migliari Riccardo, Rome: Gangemi editore. pp. 297-314.

Baltrušaitis, Jurgis. 1969. Anamorfosi o magia artificiale degli effetti meravigliosi. In: Bertolucci, P. (traduzione a cura di), Milano Adelphi.

De Rosa, Agostino, Alessio Bortot, Cristian Boscaro, Cosimo Monteleone, and Elena Trevisan. 2012. Memoria e oblio. Scoperta e rilievo digitale dell'anamorfosi murale di J.-F. Nicéron. Atti $16^{\circ}$ Conferenza Nazionale ASITA-Fiera di Vicenza 6-9 novembre 2012: 595-602.

Di Lazzaro, Paolo, and Daniele Murra. 2013. L'Anamorfismo tra arte, percezione visiva e "Prospettive bizzarre". Roma: ENEA.

Di Paola, Francesco. 2010. Le Curve di Apollonio. Tradizione ed Innovazione nei processi risolutivi. Roma: Aracne.

Eigensatz, Michael, Martin Kilian, Alexander Schiftner, Niloy J. Mitra, Helmut Pottmann, and Mark Pauly. 2010. Paneling architectural freeform surfaces. ACM SIGGRAPH 2010(45): 1-10.

Eigensatz, Michael, and Alexander Schiftner. 2012: http://www.glassonweb.com/articles/article/765. Accessed 10/2013.

Flöry, Simon, and Helmut Pottmann. 2010. Ruled Surfaces for Rationalization and Design in Architecture. LIFE information. On Responsive Information and Variations in Architecture. Proc. ACADIA 2010: 103-109.

Heumann, Andrew. 2011. http://heumanndesigntech.wordpress.com/2011/03/26/unfolding-surface-strips/ . Accessed 10/2013.

Inzerillo, Michele. 2008. Fondamenti e applicazioni di Scienza della Rappresentazione-Geometria del Disegno. http://www.inzerillomichele.eu. Accessed 10/2013.

Inzerillo, Laura. 2012. Assonometria e futuro. Roma: Aracne.

Lomazzo, Giovanni Paolo. 1585. Trattato dell'arte della pittura, scoltura et architettura. Milan: per Paolo Gottardo Pontio.

Martinez, Annalisa, Marcello Pergola, Marco Turrini, and Carla Zanoli. 2008. Perspectiva artificialis, the digital catalog of the conference sponsored by the Association Macchine Matematiche, Cremona, Museo Ugulani-Dati.

Nicéron, Jean François. 1638. La perspective curieuse, ou magie artificielle des effets merveilleux de l'optique par la vision directe, la catoptrique, par la réflexion des miroirs plats, cylindriques \& coniques, la dioptrique, par la réfraction des crystaux: Chez la veufue F. Langlois, dit Chartres, 1652, Public Library of Lyon, Paris (free e-book). http://www.books.google.com.

Piacentino, Luigi. 2013. http://www.giuliopiacentino.com/weaverbird/. Accessed 10/2013.

Pottmann, Helmut, Andreas Asperl, Michael Hofer, and Axel Kilian. 2007. Architectural Geometry. Benteley: Bentley Institute Press.

Pottmann, Helmut, Alexander Schiftner, Pengbo Bo, Heinz Schmiedhofer, Wenping Wang, Niccolo Baldassini, and Johannes Wallner. 2008. Freeform surfaces from single curved panels. ACM SIGGRAPH 2008(76): 1-10. 
Schott, Gaspard. 1657. Magia universalis naturae et artis Partis I Liber III Pars I: Würtzburg (free e-book). http://www.books.google.com.

Tonelli, Davide. 2012. Sinossi sull'ingegneria delle forme libere. In G.R.I.F.F.-Free Forms Research Group at the University of Pisa founded and coordinated by Maurizio Froli. http://www.dic.unipi.it/ davide.tonelli/files/Sinossi.pdf. Accessed 10/2013.

Villarino, Mark B. 2008. Ramanujan's Perimeter of an Ellipse, Escuela de Matematica, Universidad de Costa Rica. http://arxiv.org/abs/math/0506384v1. Accessed 10/2013.

Wallner, Johannes, and Helmut Pottmann. 2011. Geometric computing for freeform architecture. Journal of Mathematics in Industry $14:$ 1-18.

Francesco Di Paola is an Engineer, Ph.D. in "Representation and Survey of Architecture and Environment" (2007). He currently carries out activities of Assistant Professor to Department of Architecture (Darch) of Polytechnic School in Palermo. He is a Member of the scientific committee of the Tribunal of International Ph.D. at Universidad de Valladolid since 2012. He is reviewer-member of the scientific committee for the EGraFIA Association since 2014 and for the IASTED Association since 2012. He is a member of U.I.D. (Drawing Italian Union) and of ISGG since 2011. He is member of Ph.D. School of "Recupero dei contesti antichi e Processi Innovativi nell'Architettura" of the University of Palermo since 2012. He is collaborator at the Department of "Communication, Smart, green and integrated transport and Augmented reality" at the research center I.E.MES.T. in Palermo since 2012. His research interests mainly concern topics in the field of the architectural geometry, Computer Graphic and Survey. The results of these researches produced several publications in scientific journals, international and national proceedings and monographs.

Pietro Pedone is student of Building Architecture (Ingegneria Edile-Architettura, EDA) at the Polytechnic in Milano. His interests and research topics mainly include architectural geometry, parametric modeling and architecture, and procedurally generated models, subjects regarding which he has published in scientific journals, and international and national proceedings.

Laura Inzerillo is researcher of Drawing at Palermo University School of Engineering since 2004. She teaches descriptive geometry and Lab Cad at Civil Engineering and Environmental Engineering Degree Courses. Visiting Professor at Ecole d'Architetture de Paris, at Escola Tecnica Superior d'Arquitectura de Barcelona and at Columbia University. Member of UID (Italian Union of Drawing) since 1998. She is Member of the Board of Professor of the PhD course Recupero dei Contesti antichi e Processi Innovativi nell'Architettura at Palermo University. Head of the Department of "Graphic and Interactive Communication. AR" of the "Institute Euro Mediterranean of Science and Technology" IEMEST of Palermo since 2012. Her research interests mainly concern topics in the field of descriptive geometry, architectural geometry, Augmented Reality, Computer Graphics and Survey. The results of these researches produced several publications in scientific journals, international and national proceedings and monographs.

Cettina Santagati received her degree with honour in Building Engineering at University of Catania 570 (1997). Since 1999 she has been a member of the UID (Drawing Italian Union) association. In 2003 she received her Ph.D. degree in "Drawing and Survey of built heritage" from the University of Rome "La Sapienza". Since 2012 she is the head of the "Section of Innovative technologies for survey and 3D reconstruction applied to Cultural Heritage and Smart Cities" at the research center IEMEST in Palermo. Her research interest are focused on: Urban, Architectural and archaeological survey through integrated and current methods (direct, instrumental, photogrammetric, laser-scanner 3D); Analysis and experimentation of innovative methodologies and techniques aimed at the knowledge and the representation of cultural heritage (3D acquisition and reality based modeling, 3D modeling reconstruction); Graphical analysis of architecture; Descriptive Geometry. She is author and co-author of several scientific publications (books, book chapters, article in scientific Journals and International proceedings) for the most part presented at International Conferences. 